\title{
Implicit and explicit iterative algorithms for hierarchical variational inequality in uniformly smooth Banach spaces
}

\author{
Lu-Chuan Ceng ${ }^{1}$, Yung-Yih Lur ${ }^{2}$ and Ching-Feng Wen ${ }^{3,4^{*}}$ (1)
}

\begin{tabular}{l}
\hline${ }^{*}$ Correspondence: \\
cfwen@kmu.edu.tw \\
${ }^{3}$ Center for Fundamental Science; \\
and Research Center for Nonlinear \\
Analysis and Optimization, \\
Kaohsiung Medical University, \\
Kaohsiung, 80702, Taiwan \\
${ }^{4}$ Department of Medical Research, \\
Kaohsiung Medical University \\
Hospital, Kaohsiung, 80702, Taiwan \\
Full list of author information is \\
available at the end of the article
\end{tabular}

${ }^{\text {*Correspondence: }}$

cfwen@kmu.edu.tw

${ }^{3}$ Center for Fundamental Science;

and Research Center for Nonlinear

Analysis and Optimization,

Kaohsiung Medical University,

${ }^{4}$ Department of Medical Research,

Kaohsiung Medical University

Full list of author information is

available at the end of the article

\begin{abstract}
The purpose of this paper is to solve the hierarchical variational inequality with the constraint of a general system of variational inequalities in a uniformly convex and 2-uniformly smooth Banach space. We introduce implicit and explicit iterative algorithms which converge strongly to a unique solution of the hierarchical variational inequality problem. Our results improve and extend the corresponding results announced by some authors.
\end{abstract}

MSC: 49J30; 47H09; 47J20; 49M05

Keywords: system of variational inequalities; hierarchical variational inequality; nonexpansive mapping; fixed point; implicit and explicit iterative algorithms; global convergence

\section{Introduction}

Let $X$ be a real Banach space with its topological dual $X^{*}$, and $C$ be a nonempty closed convex subset of $X$. Let $T: C \rightarrow X$ be a nonlinear mapping on $C$. We denote by $\operatorname{Fix}(T)$ the set of fixed points of $T$ and by $\mathbf{R}$ the set of all real numbers. A mapping $T: C \rightarrow X$ is called $L$-Lipschitz continuous if there exists a constant $L \geq 0$ such that

$$
\|T x-T y\| \leq L\|x-y\|, \quad \forall x, y \in C .
$$

In particular, if $L=1$ then $T$ is called a nonexpansive mapping; if $L \in[0,1)$ then $T$ is called a contraction.

The normalized dual mapping $J: X \rightarrow 2^{X^{*}}$ is defined as

$$
J(x):=\left\{\varphi \in X^{*}:\langle x, \varphi\rangle=\|x\|^{2}=\|\varphi\|^{2}\right\}, \quad \forall x \in X,
$$

where $\langle\cdot, \cdot\rangle$ denotes the generalized duality pairing; see, e.g., [1] for further details.

Let $U:=\{x \in X:\|x\|=1\}$ be the unit sphere of $X$. Then the space $X$ is said to

- have a Gâteaux differentiable norm if the $\operatorname{limit} \lim _{t \rightarrow 0^{+}}(\|x+t y\|-\|x\|) / t$ exists for each $x, y \in U$.

- have a uniformly Gâteaux differentiable norm if the limit is attained uniformly for $x \in U$.

(c) The Author(s) 2017. This article is distributed under the terms of the Creative Commons Attribution 4.0 International License (http://creativecommons.org/licenses/by/4.0/), which permits unrestricted use, distribution, and reproduction in any medium, provided you give appropriate credit to the original author(s) and the source, provide a link to the Creative Commons license, and indicate if changes were made. 
- be strictly convex if and only if for $x, y \in U$ with $x \neq y$, we have

$$
\|(1-\lambda) x+\lambda y\|<1, \quad \forall \lambda \in(0,1)
$$

We note that if $X$ is smooth, then the normalized duality mapping is single-valued; and if the norm of $X$ is uniformly Gâteaux differentiable, then the normalized duality mapping is norm to weak star uniformly continuous on every bounded subset of $X$ (see [1]). In the sequel, we shall denote by $j$ the single-valued normalized duality mapping.

Let $X$ be a smooth Banach space. Let $A, B: C \rightarrow X$ be two nonlinear mappings and $\lambda, \mu$ be two positive real numbers. The general system of variational inequalities (GSVI, for short) is to find $\left(x^{*}, y^{*}\right) \in C \times C$ such that

$$
\begin{cases}\left\langle\lambda A y^{*}+x^{*}-y^{*}, j\left(x-x^{*}\right)\right\rangle \geq 0, & \forall x \in C, \\ \left\langle\mu B x^{*}+y^{*}-x^{*}, j\left(x-y^{*}\right)\right\rangle \geq 0, & \forall x \in C .\end{cases}
$$

The equivalence between GSVI (2) and the fixed point problem of some nonexpansive mapping defined on a Banach space is established in Yao et al. [2]. The authors [2] introduced and analyzed implicit and explicit iterative algorithms for solving GSVI (2) by using this equivalence, and they proved the strong convergence of the sequences generated by the proposed algorithms. Subsequently, Ceng et al. [3] proposed and analyzed an implicit algorithm of Mann's type and another explicit algorithm of Mann's type for solving GSVI (2).

If $X$ is a real Hilbert space, then GSVI (2) was introduced and studied by Ceng et al. [4]. In this case, for $A=B$, it was considered by Verma [5] (see also [6]). Further, in this case, when $x^{*}=y^{*}$, problem (2) reduces to the following classical variational inequality (in short, VI) of finding $x^{*} \in C$ such that

$$
\left\langle A x^{*}, x-x^{*}\right\rangle \geq 0, \quad \forall x \in C
$$

This problem is a fundamental problem in the variational analysis, in particular, in the optimization theory and mechanics; see, e.g., [7-12] and the references therein. A large number of algorithms for solving this problem are essentially projection algorithms that employ projections onto the feasible set $C$ of the VI, or onto some related set, so as to iteratively reach a solution. In particular, Korpelevich [13] proposed extragradient method for solving the VI in the Euclidean space. This method further has been improved by several researchers; see, e.g., $[4,14,15]$ and the references therein.

In the case of a Banach space setting, that is, if $A=B$ and $x^{*}=y^{*}$, the VI is defined as

$$
\left\langle A x^{*}, j\left(x-x^{*}\right)\right\rangle \geq 0, \quad \forall x \in C .
$$

Aoyama et al. [16] proposed an iterative scheme to find the approximate solution of (4) and proved the weak convergence of the sequences generated by the proposed scheme. It is also well known [16] that, in a smooth Banach space, this problem is equivalent to a fixed-point equation, containing a sunny nonexpansive retraction from any point of the space onto the feasible set, which is usually assumed to be closed and convex. For the complexity of the feasible set, the sunny nonexpansive retraction is difficult to compute. 
To overcome this drawback in a Hilbert space, where the retraction is a metric projection, in Yamada [17], the feasible set is assumed to be the common fixed points of a finite family of nonexpansive mappings, and an explicit hybrid steepest-descent method is introduced. In this case, the variational inequality defined on such a feasible set is also called a hierarchical variational inequality (in short, HVI). Yamada's method is then extended to solve more complex problems involving finite or infinite nonexpansive mappings (one can refer to, e.g., [18, 19] and the references therein). Zeng and Yao [19] introduced an implicit method that converges weakly to a solution of a variational inequality, containing a Lipschitz continuous and strongly monotone mapping in a Hilbert space $H$, where the feasible set is the common fixed points of a finite family of nonexpansive mappings on $H$. Ceng et al. [20] extended this result from nonexpansive mappings to Lipschitz pseudocontractive mappings and strictly pseudocontractive mappings on $H$. Recently, Buong and Anh [21] modified Yamada's result and proposed a strongly convergent implicit method.

In this paper, we are going to solve the hierarchical variational inequality with the constraint of a general system of variational inequalities in a uniformly convex and 2-uniformly smooth Banach space. We introduce implicit and explicit iterative algorithms for finding a solution of the problem and derive the strong convergence of the proposed algorithms to a unique solution of the problem. Our results improve and extend the corresponding results announced by some others, e.g., Ceng et al. [3] and Buong and Phuong [18].

\section{Preliminaries}

Let $X$ be a real Banach space with the dual space $X^{*}$. For simplicity, the norms of $X$ and $X^{*}$ are denoted by the symbol $\|\cdot\|$. Let $X$ be a nonempty closed convex subset of a real Banach space $X$. We write $x_{n} \rightarrow x$ (respectively, $x_{n} \rightarrow x$ ) to indicate that the sequence $\left\{x_{n}\right\}$ converges weakly (respectively, strongly) to $x$. A mapping $J: X \rightarrow 2^{X^{*}}$, defined by

$$
J(x)=\left\{\varphi \in X^{*}:\langle x, \varphi\rangle=\|\varphi\|^{2} \text { and }\|\varphi\|=\|x\|\right\},
$$

is called the normalized duality mapping of $X$. We know that $J(t x)=t J(x)$ for all $t>0$ and $x \in X$, and $J(-x)=-J(x)$.

Let $U:=\{x \in X:\|x\|=1\}$. A Banach space $X$ is said to be uniformly convex if for each $\varepsilon \in(0,2]$, there exists $\delta>0$ such that for any $x, y \in U,\left\|\frac{x+y}{2}\right\|>1-\delta \Rightarrow\|x-y\|<\varepsilon$. It is known that a uniformly convex Banach space is reflexive and strictly convex. Also, it is known that if a Banach space $X$ is reflexive, then $X$ is strictly convex if and only if $X^{*}$ is smooth as well as $X$ is smooth if and only if $X^{*}$ is strictly convex.

Proposition 1 ([22]) Let X be a smooth and uniformly convex Banach space, and let $r>0$. Then there exists a strictly increasing, continuous and convex function $g:[0,2 r] \rightarrow \mathbf{R}$, $g(0)=0$ such that

$$
g(\|x-y\|) \leq\|x\|^{2}-2\langle x, j(y)\rangle+\|y\|^{2}, \quad \forall x, y \in B_{r},
$$

where $B_{r}=\{x \in X:\|x\| \leq r\}$. 
Here we define a function $\rho:[0, \infty) \rightarrow[0, \infty)$ called the modulus of smoothness of $X$ as follows:

$$
\rho(\tau)=\sup \left\{\frac{1}{2}(\|x+y\|+\|x-y\|)-1: x, y \in X,\|x\|=1,\|y\|=\tau\right\} .
$$

It is known that $X$ is uniformly smooth if and only if $\lim _{\tau \rightarrow 0^{+}} \rho(\tau) / \tau=0$. Let $q$ be a fixed real number with $1<q \leq 2$. Then a Banach space $X$ is said to be $q$-uniformly smooth if there exists a constant $c>0$ such that $\rho(\tau) \leq c \tau^{q}$ for all $\tau>0$. For further details on the geometry of Banach spaces, we refer to $[1,23]$ and the references therein. Takahashi et al. [24] reminded us of the fact that no Banach space is $q$-uniformly smooth for $q>2$. So, in this paper, we focus on only a 2-uniformly smooth Banach space as in [2].

Lemma 1 ([25]) Let $q$ be a given real number with $1<q \leq 2$, and let $X$ be a q-uniformly smooth Banach space. Then

$$
\|x+y\|^{q} \leq\|x\|^{q}+q\left\langle y, J_{q}(x)\right\rangle+2\|\kappa y\|^{q}, \quad \forall x, y \in X,
$$

where $\kappa$ is the q-uniformly smooth constant of $X$ and $J_{q}$ is the generalized duality mapping from $X$ into $2^{X^{*}}$ defined by

$$
J_{q}(x)=\left\{\varphi \in X^{*}:\langle x, \varphi\rangle=\|x\|^{q},\|\varphi\|=\|x\|^{q-1}\right\}, \quad \forall x \in X .
$$

Let $D$ be a subset of $C$, and let $\Pi$ be a mapping of $C$ into $D$. Then $\Pi$ is said to be sunny if

$$
\Pi[\Pi(x)+t(x-\Pi(x))]=\Pi(x)
$$

whenever $\Pi(x)+t(x-\Pi(x)) \in C$ for $x \in C$ and $t \geq 0$. A mapping $\Pi$ of $C$ into itself is called a retraction if $\Pi^{2}=\Pi$. If a mapping $\Pi$ of $C$ into itself is a retraction, then $\Pi(z)=z$ for each $z \in R(\Pi)$, where $R(\Pi)$ is the range of $\Pi$. A subset $D$ of $C$ is called a sunny nonexpansive retract of $C$ if there exists a sunny nonexpansive retraction from $C$ onto $D$.

Lemma 2 ([26]) Let $C$ be a nonempty closed convex subset of a smooth Banach space $X$, $D$ be a nonempty subset of $C$ and $\Pi$ be a retraction of $C$ onto $D$. Then the following are equivalent:

(i) $\Pi$ is sunny and nonexpansive;

(ii) $\|\Pi(x)-\Pi(y)\|^{2} \leq\langle x-y, j(\Pi(x)-\Pi(y))\rangle, \forall x, y \in C$;

(iii) $\langle x-\Pi(x), j(y-\Pi(x))\rangle \leq 0, \forall x \in C, y \in D$.

It is well known that if $X$ is a Hilbert space, then a sunny nonexpansive retraction $\Pi_{C}$ coincides with the metric projection from $X$ onto $C$. Let $C$ be a nonempty closed convex subset of a uniformly convex and uniformly smooth Banach space $X$, and let $T$ be a nonexpansive mapping of $C$ into itself with the fixed point set $\operatorname{Fix}(T) \neq \emptyset$. Then the set $\operatorname{Fix}(T)$ is a sunny nonexpansive retract of $C$; see, e.g., [2].

Lemma 3 ([2]) Let $C$ be a nonempty closed convex subset of a real 2-uniformly smooth Banach space $X$. Let $\Pi_{C}$ be a sunny nonexpansive retraction from $X$ onto $C$. Let the mappings $A, B: C \rightarrow X$ be $\alpha$-inverse-strongly accretive and $\beta$-inverse-strongly accretive, respectively. For given $x^{*}, y^{*} \in C,\left(x^{*}, y^{*}\right)$ is a solution of GSVI (2) if and only if $x^{*} \in \operatorname{GSVI}(C, A, B)$, 
where $\operatorname{GSVI}(C, A, B)$ is the set of fixed points of the mapping $G:=\Pi_{C}(I-\lambda A) \Pi_{C}(I-\mu B)$ and $y^{*}=\Pi_{C}\left(x^{*}-\mu B x^{*}\right)$.

Proposition 2 ([27]) Let $C$ be a nonempty closed convex subset of a real 2-uniformly smooth Banach space $X$. Let the mappings $A, B: C \rightarrow X$ be $\alpha$-inverse-strongly accretive and $\beta$-inverse-strongly accretive, respectively. Then

$$
\|(I-\lambda A) x-(I-\lambda A) y\|^{2} \leq\|x-y\|^{2}+2 \lambda\left(\kappa^{2} \lambda-\alpha\right)\|A x-A y\|^{2}
$$

and

$$
\|(I-\mu B) x-(I-\mu B) y\|^{2} \leq\|x-y\|^{2}+2 \mu\left(\kappa^{2} \mu-\beta\right)\|B x-B y\|^{2} .
$$

In particular, if $0 \leq \lambda \leq \frac{\alpha}{\kappa^{2}}$ and $0 \leq \mu \leq \frac{\beta}{\kappa^{2}}$, then $I-\lambda A$ and $I-\mu B$ are nonexpansive.

Lemma 4 ([2]) Let C be a nonempty closed convex subset of a real 2-uniformly smooth Banach space $X$. Let $\Pi_{C}$ be a sunny nonexpansive retraction from $X$ onto $C$. Let the mappings $A, B: C \rightarrow X$ be $\alpha$-inverse-strongly accretive and $\beta$-inverse-strongly accretive, respectively. Let the mapping $G: C \rightarrow C$ be defined as $G:=\Pi_{C}(I-\lambda A) \Pi_{C}(I-\mu B)$. If $0 \leq \lambda \leq \frac{\alpha}{\kappa^{2}}$ and $0 \leq \mu \leq \frac{\beta}{\kappa^{2}}$, then $G: C \rightarrow C$ is nonexpansive.

Let $C$ be a nonempty closed convex subset of a uniformly convex and 2-uniformly smooth Banach space $X$. Let $\Pi_{C}$ be a sunny nonexpansive retraction from $X$ onto $C$. Let the mappings $A, B: C \rightarrow X$ be $\alpha$-inverse-strongly accretive and $\beta$-inverse-strongly accretive, respectively. Let $F: C \rightarrow X$ be $\delta$-strongly accretive and $\zeta$-strictly pseudocontractive with $\delta+\zeta>1$. Assume that $\lambda \in\left(0, \frac{\alpha}{\kappa^{2}}\right)$ and $\mu \in\left(0, \frac{\beta}{\kappa^{2}}\right)$, where $\kappa$ is the 2-uniformly smooth constant of $X$ (see Lemma 2). Very recently, in order to solve GSVI (2), Ceng et al. [3] introduced an implicit algorithm of Mann's type.

Algorithm 1 ([3]) For each $t \in(0,1)$, choose a number $\theta_{t} \in(0,1)$ arbitrarily. The net $\left\{x_{t}\right\}$ is generated by the implicit method

$$
x_{t}=t \Pi_{C}(I-\lambda A) \Pi_{C}(I-\mu B) x_{t}+(1-t) \Pi_{C}\left(I-\theta_{t} F\right) \Pi_{C}(I-\lambda A) \Pi_{C}(I-\mu B) x_{t}, \quad \forall t \in(0,1),
$$

where $x_{t}$ is a unique fixed point of the contraction

$$
W_{t}=t \Pi_{C}(I-\lambda A) \Pi_{C}(I-\mu B)+(1-t) \Pi_{C}\left(I-\theta_{t} F\right) \Pi_{C}(I-\lambda A) \Pi_{C}(I-\mu B) .
$$

It was proven in [3] that the net $\left\{x_{t}\right\}$ converges in norm, as $t \rightarrow 0^{+}$, to the unique solution $x^{*} \in \operatorname{GSVI}(C, A, B)$ to the following VI:

$$
\left\langle F\left(x^{*}\right), j\left(x-x^{*}\right)\right\rangle \geq 0, \quad \forall x \in \operatorname{GSVI}(C, A, B),
$$

provided $\lim _{t \rightarrow 0^{+}} \theta_{t}=0$. In the meantime, the authors [3] also proposed another explicit algorithm of Mann's type. 
Algorithm 2 ([3]) For arbitrarily given $x_{0} \in C$, let the sequence $\left\{x_{k}\right\}$ be generated iteratively by

$$
\begin{aligned}
x_{k+1}= & \beta_{k} x_{k}+\gamma_{k} \Pi_{C}(I-\lambda A) \Pi_{C}(I-\mu B) x_{k} \\
& +\left(1-\beta_{k}-\gamma_{k}\right) \Pi_{C}\left(I-\lambda_{k} F\right) \Pi_{C}(I-\lambda A) \Pi_{C}(I-\mu B) x_{k},
\end{aligned}
$$

where $\left\{\lambda_{k}\right\},\left\{\beta_{k}\right\}$ and $\left\{\gamma_{k}\right\}$ are three sequences in $[0,1]$ such that $\beta_{k}+\gamma_{k} \leq 1, \forall k \geq 0$.

On the other hand, a mapping $F$ with domain $D(F)$ and range $R(F)$ in $X$ is called

(a) accretive if for each $x, y \in D(F)$, there exists $j(x-y) \in J(x-y)$ such that

$$
\langle F x-F y, j(x-y)\rangle \geq 0
$$

where $J$ is the normalized duality mapping;

(b) $\delta$-strongly accretive if for each $x, y \in D(F)$, there exists $j(x-y) \in J(x-y)$ such that

$$
\langle F x-F y, j(x-y)| \geq \delta\|x-y\|^{2} \quad \text { for some } \delta \in(0,1) ;
$$

(c) $\alpha$-inverse-strongly accretive if for each $x, y \in D(F)$, there exists $j(x-y) \in J(x-y)$ such that

$$
\langle F x-F y, j(x-y)\rangle \geq \alpha\|F x-F y\|^{2} \quad \text { for some } \alpha \in(0,1) ;
$$

(d) $\zeta$-strictly pseudocontractive if for each $x, y \in D(F)$, there exists $j(x-y) \in J(x-y)$ such that

$$
\langle F x-F y, j(x-y)\rangle \leq\|x-y\|^{2}-\zeta\|x-y-(F x-F y)\|^{2} \text { for some } \zeta \in(0,1)
$$

It is easy to see that (5) can be rewritten as (see [28])

$$
\langle(I-F) x-(I-F) y, j(x-y)| \geq \zeta\|(I-F) x-(I-F) y\|^{2},
$$

where $I$ denotes the identity mapping of $X$. Clearly, if $F$ is $\zeta$-strictly pseudocontractive with $\zeta=0$, then it is said to be pseudocontractive. It is not hard to find that every nonexpansive mapping is pseudocontractive.

Let $C$ be a nonempty closed convex subset of a smooth Banach space $X$ and $\left\{T_{i}\right\}_{i=1}^{\infty}$ be an infinite family of nonexpansive self-mappings on $C$. Then we set $\mathcal{F}:=\bigcap_{i=1}^{\infty} \operatorname{Fix}\left(T_{i}\right)$. In 2013, Buong and Phuong [18] considered the following HVI with $C=X$ : find $x^{*} \in \mathcal{F}$ such that

$$
\left\langle F\left(x^{*}\right), j\left(x-x^{*}\right)\right| \geq 0, \quad \forall x \in \mathcal{F} .
$$

In the case where $X=H$, a Hilbert space, we have $J=I$, and hence problem (7) reduces to the HVI: find $x^{*} \in \mathcal{F}$ such that

$$
\left\langle F\left(x^{*}\right), x-x^{*}\right\rangle \geq 0, \quad \forall x \in \mathcal{F} .
$$


Assume that $\mathcal{F}=\bigcap_{i=1}^{N} \operatorname{Fix}\left(T_{i}\right)$ is the set of common fixed points of a family of $N$ nonexpansive mappings $T_{i}$ on $H$, and $F$ is an $L$-Lipschitz continuous and $\eta$-strongly monotone mapping, i.e., $\|F x-F y\| \leq L\|x-y\|$ and $\langle F x-F y, x-y\rangle \geq \eta\|x-y\|^{2}$ for all $x, y \in H$. Zeng and Yao [19] introduced the following implicit iteration: for an arbitrarily initial point $x_{0} \in H$, the sequence $\left\{x_{k}\right\}_{k=1}^{\infty}$ is generated as follows:

$$
x_{k}=\beta_{k} x_{k-1}+\left(1-\beta_{k}\right)\left[T_{[k]} x_{k}-\lambda_{k} \mu F\left(T_{[k]} x_{k}\right)\right], \quad \forall k \geq 1,
$$

where $T_{[n]}=T_{n \bmod N}$, for integer $n \geq 1$, with the mod function taking values in the set $\{1,2, \ldots, N\}$. They proved the following result.

Theorem 3 ([19]) Let $H$ be a real Hilbert space, and let $F: H \rightarrow H$ be a mapping such that, for some positive constants $L$ and $\eta, F$ is L-Lipschitz continuous and $\eta$-strongly monotone. Let $\left\{T_{i}\right\}_{i=1}^{N}$ be $N$ nonexpansive mappings on $H$ such that $\mathcal{F}: \bigcap_{i=1}^{N} \operatorname{Fix}\left(T_{i}\right) \neq \emptyset$. Let $\mu \in\left(0,2 \eta / L^{2}\right), x_{0} \in H,\left\{\lambda_{k}\right\}_{k=1}^{\infty} \subset[0,1)$ and $\left\{\beta_{k}\right\}_{k=1}^{\infty} \subset(0,1)$ satisfying the conditions $\sum_{k=1}^{\infty} \lambda_{k}<\infty$, and let $a \leq \beta_{k} \leq b, k \geq 1$, for some $a, b \in(0,1)$. Then the sequence $\left\{x_{k}\right\}_{k=0}^{\infty}$, defined by (9), converges weakly to $x^{*} \in \mathcal{F}$.

Recently, for deriving the strong convergence and weakening the condition on $\lambda_{k}$, Buong and Anh [21] proposed the following implicit iteration method:

$$
x_{t}=T^{t} x_{t}, \quad T^{t}:=T_{0}^{t} T_{N}^{t} \cdots T_{1}^{t}, t \in(0,1)
$$

where the sequence $\left\{T_{i}^{t}\right\}_{i=0}^{N}$ is defined by

$$
\begin{cases}T_{i}^{t} x:=\left(1-\beta_{t}^{i}\right) x+\beta_{t}^{i} T_{i} x, & i=1, \ldots, N \\ T_{0}^{t} y:=\left(I-\lambda_{t} \mu F\right) y, & x, y \in H\end{cases}
$$

and proved that the nets $\left\{x_{t}\right\}$, defined by (10)-(11), converge strongly to an element $x^{*}$ in (8). Under the assumptions that $N=1, X$ is a real reflexive and strictly convex Banach space with a uniformly Gâteaux differentiable norm, and $T$ is a continuous pseudocontractive mapping, Ceng et al. [29] proved the following result.

Theorem 4 ([29]) Let $F$ be a $\delta$-strongly accretive and $\zeta$-strictly pseudocontractive mapping with $\delta+\zeta>1$, and let $T$ be a continuous and pseudocontractive mapping on $X$, which is a real reflexive and strictly convex Banach space with a uniformly Gâteaux differentiable norm such that $\mathcal{F}:=\operatorname{Fix}(T) \neq \emptyset$. For each $t \in(0,1)$, choose a number $\mu_{t} \in(0,1)$ arbitrarily, and let $\left\{z_{t}\right\}$ be defined by

$$
z_{t}=t\left(I-\mu_{t} F\right) z_{t}+(1-t) T z_{t}
$$

Then, as $t \rightarrow 0^{+},\left\{z_{t}\right\}$ converges strongly to $x^{*} \in \mathcal{F}$. 
In [30], Takahashi introduced the following $W$-mapping which is generated by $T_{k}, T_{k-1}$, $\ldots, T_{1}$ and real numbers $\alpha_{k}, \alpha_{k-1}, \ldots, \alpha_{1}$ as follows:

$$
\left\{\begin{array}{l}
U_{k, k+1}=I \\
U_{k, k}=\alpha_{k} T_{k} U_{k, k+1}+\left(1-\alpha_{k}\right) I \\
U_{k, k-1}=\alpha_{k-1} T_{k-1} U_{k, k}+\left(1-\alpha_{k-1}\right) I \\
\cdots \\
U_{k, 2}=\alpha_{2} T_{2} U_{k, 3}+\left(1-\alpha_{2}\right) I \\
W_{k}=U_{k, 1}=\alpha_{1} T_{1} U_{k, 2}+\left(1-\alpha_{1}\right) I
\end{array}\right.
$$

Kikkawa and Takahashi [31] considered the following strongly convergent implicit method:

$$
S_{k} x=\left(1-\frac{1}{k}\right) U x+\frac{1}{k} f(x), \quad \text { and } \quad U x=\lim _{k \rightarrow \infty} W_{k} x=\lim _{k \rightarrow \infty} U_{k, 1} x .
$$

However, the method (14) is very difficult to be grasped due to the limit mapping $U$.

Motivated by methods (10) and (12), Buong and Phuong [18] considered two implicit methods by introducing a mapping $V_{k}$ defined by

$$
V_{k}=V_{k}^{1}, \quad V_{k}^{i}=T^{i} T^{i+1} \cdots T^{k}, \quad T^{i}=\left(1-\alpha_{i}\right) I+\alpha_{i} T_{i}, \quad i=1,2, \ldots, k,
$$

where

$$
\alpha_{i} \in(0,1) \quad \text { and } \quad \sum_{i=1}^{\infty} \alpha_{i}<\infty .
$$

In both methods, the iteration sequence $\left\{x_{k}\right\}_{k=1}^{\infty}$ is defined, respectively, by

$$
x_{k}=V_{k}\left(I-\lambda_{k} F\right) x_{k}, \quad \forall k \geq 1,
$$

and

$$
x_{k}=\gamma_{k}\left(I-\lambda_{k} F\right) x_{k}+\left(I-\gamma_{k}\right) V_{k} x_{k}, \quad \forall k \geq 1,
$$

where $\lambda_{k}$ and $\gamma_{k}$ are the positive parameters satisfying some additional conditions. The strong convergence theorems for methods (17) and (18) are also established.

We will make use of the following well-known results.

Lemma 5 Let $X$ be a real normed linear space. Then the following inequality holds:

$$
\|x+y\|^{2} \leq\|x\|^{2}+2\langle y, j(x+y)\rangle, \quad \forall x, y \in X, \forall j(x+y) \in J(x+y) .
$$

Lemma 6 ([32]) Let $C$ be a nonempty closed convex subset of a uniformly convex Banach space $X$ and $T: C \rightarrow C$ be a nonexpansive mapping with $\operatorname{Fix}(T) \neq \emptyset$. If $\left\{x_{n}\right\}$ is a sequence of $C$ such that $x_{n} \rightarrow x$ and $(I-T) x_{n} \rightarrow y$, then $(I-T) x=y$. In particular, if $y=0$, then $x \in \operatorname{Fix}(T)$. 
Lemma 7 ([2]) Let C be a nonempty closed convex subset of a real smooth Banach space $X$. Assume that the mapping $F: C \rightarrow X$ is accretive and weakly continuous along segments $($ that is, $F(x+t y) \rightarrow F(x)$ as $t \rightarrow 0)$. Then the variational inequality

$$
x^{*} \in C, \quad\left\langle F\left(x^{*}\right), j\left(x-x^{*}\right)\right| \geq 0, \quad \forall x \in C
$$

is equivalent to the following Minty type variational inequality:

$$
x^{*} \in C, \quad\left\langle F(x), j\left(x-x^{*}\right)\right| \geq 0, \quad \forall x \in C .
$$

Lemma 8 ([3]) Let $X$ be a real smooth Banach space and $F: C \rightarrow X$ be a mapping.

(a) If $F$ is $\zeta$-strictly pseudocontractive, then $F$ is Lipschitz continuous with constant $1+\frac{1}{\zeta}$.

(b) If $F$ is $\delta$-strongly accretive and $\zeta$-strictly pseudocontractive with $\delta+\zeta>1$, then $I-F$ is contractive with constant $\sqrt{\frac{1-\delta}{\zeta}} \in(0,1)$.

(c) If $F$ is $\delta$-strongly accretive and $\zeta$-strictly pseudocontractive with $\delta+\zeta>1$, then for any fixed number $\lambda \in(0,1), I-\lambda F$ is contractive with constant $1-\lambda\left(1-\sqrt{\frac{1-\delta}{\zeta}}\right) \in(0,1)$.

\section{Iterative algorithms and convergence criteria}

In this section, we study iterative methods for computing approximate solutions of the HVI (for an infinite family of nonexpansive mappings) with a GSVI constraint. We introduce implicit and explicit iterative algorithms for solving such a problem. We show the strong convergence theorems for the sequences generated by the proposed algorithms.

The following lemmas will be used to prove our main results in the sequel.

Lemma 9 ([18]) Let C be a nonempty closed convex subset of a strictly convex Banach space $X$, and let $\left\{T_{i}\right\}_{i=1}^{k}, k \geq 1$, be $k$ nonexpansive self-mappings on $C$ such that the set of common fixed points $\mathcal{F}:=\bigcap_{i=1}^{k} \operatorname{Fix}\left(T_{i}\right) \neq \emptyset$. Let $a, b$ and $\alpha_{i}, i=1,2, \ldots, k$, be real numbers such that $0<a \leq \alpha_{i} \leq b<1$, and let $V_{k}$ be a mapping defined by (15) for all $k \geq 1$. Then $\operatorname{Fix}\left(V_{k}\right)=\mathcal{F}$.

Lemma 10 ([18]) Let $C$ be a nonempty closed convex subset of a Banach space $X$, and let $\left\{T_{i}\right\}_{i=1}^{\infty}$ be an infinite family of nonexpansive self-mappings on $C$ such that the set of common fixed points $\mathcal{F}:=\bigcap_{i=1}^{\infty} \operatorname{Fix}\left(T_{i}\right) \neq \emptyset$. Let $V_{k}$ be a mapping defined by (15), and let $\alpha_{i}$ satisfy (16). Then, for each $x \in C$ and $i \geq 1, \lim _{k \rightarrow \infty} V_{k}^{i} x$ exists.

\section{Remark 1}

(i) We can define the mappings

$$
V_{\infty}^{i} x:=\lim _{k \rightarrow \infty} V_{k}^{i} x \quad \text { and } \quad V x:=V_{\infty}^{1} x=\lim _{k \rightarrow \infty} V_{k} x, \quad \forall x \in C .
$$

(ii) It can be readily seen from the proof of Lemma 10 that if $D$ is a nonempty and bounded subset of $C$, then the following holds:

$$
\lim _{k \rightarrow \infty} \sup _{x \in D}\left\|V_{k}^{i} x-V_{\infty}^{i} x\right\|=0, \quad \forall i \geq 1 .
$$

In particular, whenever $i=1$, we have

$$
\lim _{k \rightarrow \infty} \sup _{x \in D}\left\|V_{k} x-V x\right\|=0 .
$$


Lemma 11 ([18]) Let $C$ be a nonempty closed convex subset of a strictly convex Banach space $X$, and let $\left\{T_{i}\right\}_{i=1}^{\infty}$ be an infinite family of nonexpansive self-mappings on $C$ such that the set of common fixed points $\mathcal{F}:=\bigcap_{i=1}^{\infty} \operatorname{Fix}\left(T_{i}\right) \neq \emptyset$. Let $\alpha_{i}$ satisfy the first condition in (16). Then $\operatorname{Fix}(V)=\mathcal{F}$.

Lemma 12 ([33]) Let $\left\{x_{n}\right\}$ and $\left\{z_{n}\right\}$ be bounded sequences in a Banach space $X$, and let $\left\{\alpha_{k}\right\}$ be a sequence in $[0,1]$ such that

$$
0<\liminf _{k \rightarrow \infty} \alpha_{k} \leq \limsup _{k \rightarrow \infty} \alpha_{k}<1
$$

Suppose that $x_{k+1}=\alpha_{k} x_{k}+\left(1-\alpha_{k}\right) z_{k}, \forall k \geq 1$, and

$$
\limsup _{k \rightarrow \infty}\left(\left\|z_{k+1}-z_{k}\right\|-\left\|x_{k+1}-x_{k}\right\|\right) \leq 0
$$

Then $\lim _{k \rightarrow \infty}\left\|z_{k}-x_{k}\right\|=0$.

Lemma 13 ([34]) Assume that $\left\{a_{k}\right\}$ is a sequence of nonnegative real numbers such that

$$
a_{k+1} \leq\left(1-\gamma_{k}\right) a_{k}+\gamma_{k} \delta_{k}, \quad \forall k \geq 1
$$

where $\left\{\gamma_{k}\right\}$ is a sequence in $[0,1]$ and $\left\{\delta_{k}\right\}$ is a sequence in $\mathbf{R}$ such that

(i) $\sum_{k=1}^{\infty} \gamma_{k}=\infty$;

(ii) $\lim _{\sup } \sin _{k \rightarrow \infty} \delta_{k} \leq 0$ or $\sum_{k=1}^{\infty}\left|\gamma_{k} \delta_{k}\right|<\infty$.

Then $\lim _{k \rightarrow \infty} a_{k}=0$.

Now, we are in a position to prove the following main results.

Theorem 5 Let $C$ be a nonempty closed convex subset of a uniformly convex and 2uniformly smooth Banach space $X$. Let $\Pi_{C}$ be a sunny nonexpansive retraction from $X$ onto $C$. Let the mappings $A, B: C \rightarrow X$ be $\alpha$-inverse-strongly accretive and $\beta$-inverse-strongly accretive, respectively. Let $F: C \rightarrow X$ be $\delta$-strongly accretive and $\zeta$-strictly pseudocontractive with $\delta+\zeta>1$. Assume that $\lambda \in\left(0, \frac{\alpha}{\kappa^{2}}\right)$ and $\mu \in\left(0, \frac{\beta}{\kappa^{2}}\right)$ where $\kappa$ is the 2-uniformly smooth constant of $X$. Let $\left\{T_{i}\right\}_{i=1}^{\infty}$ be an infinite family of nonexpansive self-mappings on $C$ such that $\mathcal{F}:=\bigcap_{i=1}^{\infty} \operatorname{Fix}\left(T_{i}\right) \cap \operatorname{GSVI}(C, A, B) \neq \emptyset$. Let $\left\{V_{k}\right\}_{k=1}^{\infty}$ be defined by (15) and (16). Let $\left\{x_{k}\right\}_{k=1}^{\infty}$ be defined by

$$
\begin{aligned}
x_{k}= & \gamma_{k} \Pi_{C}\left(I-\lambda_{k} F\right) \Pi_{C}(I-\lambda A) \Pi_{C}(I-\mu B) V_{k} x_{k} \\
& +\left(1-\gamma_{k}\right) \Pi_{C}(I-\lambda A) \Pi_{C}(I-\mu B) V_{k} x_{k}, \quad \forall k \geq 1,
\end{aligned}
$$

where $\left\{\gamma_{k}\right\}$ and $\left\{\lambda_{k}\right\}$ are sequences in $(0,1]$ such that $\gamma_{k} \rightarrow 0$ and $\lambda_{k} \rightarrow 0$ as $k \rightarrow \infty$. Then $\left\{x_{k}\right\}_{k=1}^{\infty}$ converges strongly to a unique solution $x^{*} \in \mathcal{F}$ to the following VI:

$$
\left\langle F\left(x^{*}\right), j\left(x-x^{*}\right)\right| \geq 0, \quad \forall x \in \mathcal{F}
$$

Proof Let the mapping $G: C \rightarrow C$ be defined as $G:=\Pi_{C}(I-\lambda A) \Pi_{C}(I-\mu B)$, where $0<\lambda<$ $\frac{\alpha}{\kappa^{2}}$ and $0<\mu<\frac{\beta}{\kappa^{2}}$. In terms of Lemma 4 we know that $G: C \rightarrow C$ is nonexpansive. Then 
the implicit iterative scheme can be rewritten as

$$
x_{k}=\gamma_{k} \Pi_{C}\left(I-\lambda_{k} F\right) G V_{k} x_{k}+\left(1-\gamma_{k}\right) G V_{k} x_{k}, \quad \forall k \geq 1 .
$$

Consider the mapping $U_{k} x=\gamma_{k} \Pi_{C}\left(I-\lambda_{k} F\right) G V_{k} x+\left(1-\gamma_{k}\right) G V_{k} x, \forall x \in C$. From Lemmas 4 and 8 (c), it follows that for each $x, y \in C$,

$$
\begin{aligned}
\left\|U_{k} x-U_{k} y\right\|= & \| \gamma_{k}\left(\Pi_{C}\left(I-\lambda_{k} F\right) G V_{k} x-\Pi_{C}\left(I-\lambda_{k} F\right) G V_{k} y\right) \\
& +\left(1-\gamma_{k}\right)\left(G V_{k} x-G V_{k} y\right) \| \\
\leq & \gamma_{k}\left\|\left(I-\lambda_{k} F\right) G V_{k} x-\left(I-\lambda_{k} F\right) G V_{k} y\right\|+\left(1-\gamma_{k}\right)\left\|G V_{k} x-G V_{k} y\right\| \\
\leq & \gamma_{k}\left(1-\lambda_{k} \tau\right)\left\|G V_{k} x-G V_{k} y\right\|+\left(1-\gamma_{k}\right)\left\|G V_{k} x-G V_{k} y\right\| \\
= & \left(1-\gamma_{k} \lambda_{k} \tau\right)\left\|G V_{k} x-G V_{k} y\right\| \\
\leq & \left(1-\gamma_{k} \lambda_{k} \tau\right)\|x-y\|,
\end{aligned}
$$

where $\tau=1-\sqrt{\frac{1-\delta}{\zeta}} \in(0,1)$ (by using $\delta+\zeta>1$ ). Due to $\gamma_{k} \lambda_{k} \tau \in(0,1), U_{k}$ is a contraction of $C$ into itself. Hence, by Banach's contraction principle, there exists a unique element $x_{k} \in C$ satisfying (20).

Next, we divide the rest of the proof into several steps.

Step 1. We show that $\left\{x_{k}\right\}_{k=1}^{\infty}$ is bounded. Indeed, take an arbitrarily given $p \in \mathcal{F}$. Then we have $V_{k} p=p$ and $G p=p$. Hence, by Lemma 8 (c) we get

$$
\begin{aligned}
\left\|x_{k}-p\right\|^{2} & =\left\|\gamma_{k} \Pi_{C}\left(I-\lambda_{k} F\right) G V_{k} x_{k}+\left(1-\gamma_{k}\right) G V_{k} x_{k}-p\right\|^{2} \\
& \leq \gamma_{k}\left\|\Pi_{C}\left(I-\lambda_{k} F\right) G V_{k} x_{k}-p\right\|^{2}+\left(1-\gamma_{k}\right)\left\|G V_{k} x_{k}-p\right\|^{2} \\
& \leq \gamma_{k}\left\|\left(I-\lambda_{k} F\right) G V_{k} x_{k}-p\right\|^{2}+\left(1-\gamma_{k}\right)\left\|G V_{k} x_{k}-p\right\|^{2} \\
& =\gamma_{k}\left\|\left(I-\lambda_{k} F\right) G V_{k} x_{k}-\left(I-\lambda_{k} F\right) p-\lambda_{k} F(p)\right\|^{2}+\left(1-\gamma_{k}\right)\left\|G V_{k} x_{k}-p\right\|^{2} \\
& \leq \gamma_{k}\left[\left(1-\lambda_{k} \tau\right)\left\|G V_{k} x_{k}-p\right\|+\lambda_{k}\|F(p)\|\right]^{2}+\left(1-\gamma_{k}\right)\left\|G V_{k} x_{k}-p\right\|^{2} \\
& \leq \gamma_{k}\left[\left(1-\lambda_{k} \tau\right)\left\|G V_{k} x_{k}-p\right\|^{2}+\lambda_{k} \tau^{-1}\|F(p)\|^{2}\right]+\left(1-\gamma_{k}\right)\left\|G V_{k} x_{k}-p\right\|^{2} \\
& =\left(1-\gamma_{k} \lambda_{k} \tau\right)\left\|G V_{k} x_{k}-p\right\|^{2}+\gamma_{k} \lambda_{k} \tau^{-1}\|F(p)\|^{2} \\
& \leq\left(1-\gamma_{k} \lambda_{k} \tau\right)\left\|x_{k}-p\right\|^{2}+\gamma_{k} \lambda_{k} \tau^{-1}\|F(p)\|^{2} .
\end{aligned}
$$

Therefore, $\left\|x_{k}-p\right\| \leq\|F(p)\| / \tau$, which also leads to the boundedness of $\left\{x_{k}\right\}_{k=1}^{\infty}$. So, the sequences $\left\{V_{k} x_{k}\right\}_{k=1}^{\infty},\left\{y_{k}\right\}_{k=1}^{\infty}$ and $\left\{F\left(y_{k}\right)\right\}_{k=1}^{\infty}$, where $y_{k}=G V_{k} x_{k}$, are also bounded. Since $\gamma_{k} \rightarrow 0$ as $k \rightarrow \infty$, and the following relation holds

$$
\begin{aligned}
\left\|x_{k}-G V_{k} x_{k}\right\| & =\gamma_{k}\left\|\Pi_{C}\left(I-\lambda_{k} F\right) G V_{k} x_{k}-G V_{k} x_{k}\right\| \\
& \leq \gamma_{k}\left\|\left(I-\lambda_{k} F\right) G V_{k} x_{k}-G V_{k} x_{k}\right\| \\
& =\gamma_{k} \lambda_{k}\left\|F\left(y_{k}\right)\right\| \leq \gamma_{k}\left\|F\left(y_{k}\right)\right\|,
\end{aligned}
$$

we obtain from the boundedness of $\left\{F\left(y_{k}\right)\right\}$ that $\left\|x_{k}-G V_{k} x_{k}\right\| \rightarrow 0$ as $k \rightarrow \infty$. 
Step 2. We show that $\left\|z_{k}-G z_{k}\right\| \rightarrow 0$ as $k \rightarrow \infty$, where $z_{k}=V_{k} x_{k}$ for all $k \geq 1$. Indeed, for simplicity, put $q=\Pi_{C}(p-\mu B p)$ and $u_{k}=\Pi_{C}\left(z_{k}-\mu B z_{k}\right)$. Then $y_{k}=G z_{k}=\Pi_{C}\left(u_{k}-\lambda A u_{k}\right)$ for all $k \geq 1$. From Lemma 2 , we have

$$
\begin{aligned}
\left\|u_{k}-q\right\|^{2} & =\left\|\Pi_{C}\left(z_{k}-\mu B z_{k}\right)-\Pi_{C}(p-\mu B p)\right\|^{2} \\
& \leq\left\|z_{k}-p-\mu\left(B z_{k}-B p\right)\right\|^{2} \\
& \leq\left\|z_{k}-p\right\|^{2}-2 \mu\left(\beta-\kappa^{2} \mu\right)\left\|B z_{k}-B p\right\|^{2} \\
& \leq\left\|x_{k}-p\right\|^{2}-2 \mu\left(\beta-\kappa^{2} \mu\right)\left\|B z_{k}-B p\right\|^{2},
\end{aligned}
$$

and

$$
\begin{aligned}
\left\|y_{k}-p\right\|^{2} & =\left\|\Pi_{C}\left(u_{k}-\lambda A u_{k}\right)-\Pi_{C}(q-\lambda A q)\right\|^{2} \\
& \leq\left\|u_{k}-q-\lambda\left(A u_{k}-A q\right)\right\|^{2} \\
& \leq\left\|u_{k}-q\right\|^{2}-2 \lambda\left(\alpha-\kappa^{2} \lambda\right)\left\|A u_{k}-A q\right\|^{2} .
\end{aligned}
$$

Substituting (22) for (23), we obtain

$$
\begin{aligned}
\left\|y_{k}-p\right\|^{2} \leq & \left\|x_{k}-p\right\|^{2}-2 \mu\left(\beta-\kappa^{2} \mu\right)\left\|B z_{k}-B p\right\|^{2} \\
& -2 \lambda\left(\alpha-\kappa^{2} \lambda\right)\left\|A u_{k}-A q\right\|^{2} .
\end{aligned}
$$

From (21) and (24), we have

$$
\begin{aligned}
\left\|x_{k}-p\right\|^{2} \leq & \left(1-\gamma_{k} \lambda_{k} \tau\right)\left\|G z_{k}-p\right\|^{2}+\gamma_{k} \lambda_{k} \tau^{-1}\|F(p)\|^{2} \\
\leq & \left\|G z_{k}-p\right\|^{2}+\gamma_{k} \tau^{-1}\|F(p)\|^{2} \\
\leq & \left\|x_{k}-p\right\|^{2}-2 \mu\left(\beta-\kappa^{2} \mu\right)\left\|B z_{k}-B p\right\|^{2} \\
& -2 \lambda\left(\alpha-\kappa^{2} \lambda\right)\left\|A u_{k}-A q\right\|^{2}+\gamma_{k} \frac{\|F(p)\|^{2}}{\tau},
\end{aligned}
$$

which immediately yields

$$
2 \mu\left(\beta-\kappa^{2} \mu\right)\left\|B z_{k}-B p\right\|^{2}+2 \lambda\left(\alpha-\kappa^{2} \lambda\right)\left\|A u_{k}-A q\right\|^{2} \leq \gamma_{k} \frac{\|F(p)\|^{2}}{\tau} .
$$

So, from $\lambda \in\left(0, \frac{\alpha}{\kappa^{2}}\right), \mu \in\left(0, \frac{\beta}{\kappa^{2}}\right)$ and $\gamma_{k} \rightarrow 0$ as $k \rightarrow \infty$, we deduce that

$$
\lim _{k \rightarrow \infty}\left\|B z_{k}-B p\right\|=0 \quad \text { and } \quad \lim _{k \rightarrow \infty}\left\|A u_{k}-A q\right\|=0 .
$$

Utilizing Proposition 1 and Lemma 2, we have

$$
\begin{aligned}
\left\|u_{k}-q\right\|^{2} & =\left\|\Pi_{C}\left(z_{k}-\mu B z_{k}\right)-\Pi_{C}(p-\mu B p)\right\|^{2} \\
& \leq\left\langle\left(z_{k}-\mu B z_{k}\right)-(p-\mu B p), j\left(u_{k}-q\right)\right\rangle \\
& =\left\langle\left(z_{k}-p, j\left(u_{k}-q\right)\right\rangle+\mu\left\langle B p-B z_{k}, j\left(u_{k}-q\right)\right\rangle\right.
\end{aligned}
$$




$$
\begin{aligned}
\leq & \frac{1}{2}\left[\left\|z_{k}-p\right\|^{2}+\left\|u_{k}-q\right\|^{2}-g_{1}\left(\left\|z_{k}-u_{k}-(p-q)\right\|\right)\right] \\
& +\mu\left\|B p-B z_{k}\right\|\left\|u_{k}-q\right\| \\
\leq & \frac{1}{2}\left[\left\|x_{k}-p\right\|^{2}+\left\|u_{k}-q\right\|^{2}-g_{1}\left(\left\|z_{k}-u_{k}-(p-q)\right\|\right)\right] \\
& +\mu\left\|B p-B z_{k}\right\|\left\|u_{k}-q\right\|,
\end{aligned}
$$

which implies that

$$
\begin{gathered}
\left\|u_{k}-q\right\|^{2} \leq \\
+x_{k}-p \|^{2}-g_{1}\left(\left\|z_{k}-u_{k}-(p-q)\right\|\right) \\
+2 \mu\left\|B p-B z_{k}\right\|\left\|u_{k}-q\right\| .
\end{gathered}
$$

In the same way, we derive

$$
\begin{aligned}
\left\|y_{k}-p\right\|^{2}= & \left\|\Pi_{C}\left(u_{k}-\lambda A u_{k}\right)-\Pi_{C}(q-\lambda A q)\right\|^{2} \\
\leq & \left\langle u_{k}-\lambda A u_{k}-(q-\lambda A q), j\left(y_{k}-p\right)\right\rangle \\
= & \left\langle u_{k}-q, j\left(y_{k}-p\right)\right\rangle+\lambda\left\langle A q-A u_{k}, j\left(y_{k}-p\right)\right\rangle \\
\leq & \frac{1}{2}\left[\left\|u_{k}-q\right\|^{2}+\left\|y_{k}-p\right\|^{2}-g_{2}\left(\left\|u_{k}-y_{k}+(p-q)\right\|\right)\right] \\
& +\lambda\left\|A q-A u_{k}\right\|\left\|y_{k}-p\right\|,
\end{aligned}
$$

which implies that

$$
\left\|y_{k}-p\right\|^{2} \leq\left\|u_{k}-q\right\|^{2}-g_{2}\left(\left\|u_{k}-y_{k}+(p-q)\right\|\right)+2 \lambda\left\|A q-A u_{k}\right\|\left\|y_{k}-p\right\| .
$$

Substituting (26) for (27), we get

$$
\begin{gathered}
\left\|y_{k}-p\right\|^{2} \leq\left\|x_{k}-p\right\|^{2}-g_{1}\left(\left\|z_{k}-u_{k}-(p-q)\right\|\right)-g_{2}\left(\left\|u_{k}-y_{k}+(p-q)\right\|\right) \\
+2 \mu\left\|B p-B z_{k}\right\|\left\|u_{k}-q\right\|+2 \lambda\left\|A q-A u_{k}\right\|\left\|y_{k}-p\right\| .
\end{gathered}
$$

So, from (21) and (28) it follows that

$$
\begin{aligned}
\left\|x_{k}-p\right\|^{2} \leq & \left(1-\gamma_{k} \lambda_{k} \tau\right)\left\|G z_{k}-p\right\|^{2}+\gamma_{k} \lambda_{k} \tau^{-1}\|F(p)\|^{2} \\
\leq & \left\|y_{k}-p\right\|^{2}+\gamma_{k} \frac{\|F(p)\|^{2}}{\tau} \\
\leq & \left\|x_{k}-p\right\|^{2}-g_{1}\left(\left\|z_{k}-u_{k}-(p-q)\right\|\right)-g_{2}\left(\left\|u_{k}-y_{k}+(p-q)\right\|\right) \\
& +2 \mu\left\|B p-B z_{k}\right\|\left\|u_{k}-q\right\|+2 \lambda\left\|A q-A u_{k}\right\|\left\|y_{k}-p\right\|+\gamma_{k} \frac{\|F(p)\|^{2}}{\tau},
\end{aligned}
$$

which hence leads to

$$
\begin{aligned}
& g_{1}\left(\left\|z_{k}-u_{k}-(p-q)\right\|\right)+g_{2}\left(\left\|u_{k}-y_{k}+(p-q)\right\|\right) \\
& \quad \leq 2 \mu\left\|B p-B z_{k}\right\|\left\|u_{k}-q\right\|+2 \lambda\left\|A q-A u_{k}\right\|\left\|y_{k}-p\right\|+\gamma_{k} \frac{\|F(p)\|^{2}}{\tau} .
\end{aligned}
$$


From (25), $\gamma_{k} \rightarrow 0$ as $k \rightarrow \infty$, and the boundedness of $\left\{u_{k}\right\}$ and $\left\{y_{k}\right\}$, we deduce that

$$
\lim _{k \rightarrow \infty} g_{1}\left(\left\|z_{k}-u_{k}-(p-q)\right\|\right)=0 \quad \text { and } \quad \lim _{k \rightarrow \infty} g_{2}\left(\left\|u_{k}-y_{k}+(p-q)\right\|\right)=0
$$

Utilizing the properties of $g_{1}$ and $g_{2}$, we conclude that

$$
\lim _{k \rightarrow \infty}\left\|z_{k}-u_{k}-(p-q)\right\|=0 \quad \text { and } \quad \lim _{k \rightarrow \infty}\left\|u_{k}-y_{k}+(p-q)\right\|=0
$$

From (30), we get

$$
\left\|z_{k}-y_{k}\right\| \leq\left\|z_{k}-u_{k}-(p-q)\right\|+\left\|u_{k}-y_{k}+(p-q)\right\| \rightarrow 0 \quad \text { as } k \rightarrow \infty .
$$

That is,

$$
\lim _{k \rightarrow \infty}\left\|z_{k}-G z_{k}\right\|=\lim _{k \rightarrow \infty}\left\|z_{k}-y_{k}\right\|=0
$$

This together with $\left\|x_{k}-G V_{k} x_{k}\right\| \rightarrow 0$ implies that

$$
\lim _{k \rightarrow \infty}\left\|x_{k}-y_{k}\right\|=0 \quad \text { and } \quad \lim _{k \rightarrow \infty}\left\|x_{k}-V_{k} x_{k}\right\|=\lim _{k \rightarrow \infty}\left\|x_{k}-z_{k}\right\|=0 .
$$

Step 3. We show that $\omega_{w}\left(x_{k}\right) \subset \mathcal{F}$, where

$$
\omega_{w}\left(x_{k}\right)=\left\{x \in C: x_{k_{i}} \rightarrow x \text { for some subsequence }\left\{x_{k_{i}}\right\} \text { of }\left\{x_{k}\right\}\right\} .
$$

Indeed, we first claim that $\left\|x_{k}-V x_{k}\right\| \rightarrow 0$ as $k \rightarrow \infty$. It is easy to see from Remark 1(ii) that if $D$ is a nonempty and bounded subset of $C$, then, for $\varepsilon>0$, there exists $k_{0}>i$ such that for all $k>k_{0}$

$$
\sup _{x \in D}\left\|V_{k}^{i} x-V_{\infty}^{i} x\right\| \leq \varepsilon
$$

Taking $D=\left\{x_{k}: k \geq 1\right\}$ and $i=1$, we have

$$
\left\|V_{k} x_{k}-V x_{k}\right\| \leq \sup _{x \in D}\left\|V_{k} x-V x\right\| \leq \varepsilon
$$

So, it follows that

$$
\lim _{k \rightarrow \infty}\left\|V_{k} x_{k}-V x_{k}\right\|=0
$$

Noting that

$$
\begin{aligned}
\left\|G V x_{k}-V x_{k}\right\| & \leq\left\|G V x_{k}-G V_{k} x_{k}\right\|+\left\|G V_{k} x_{k}-V_{k} x_{k}\right\|+\left\|V_{k} x_{k}-V x_{k}\right\| \\
& \leq\left\|V x_{k}-V_{k} x_{k}\right\|+\left\|G z_{k}-z_{k}\right\|+\left\|V_{k} x_{k}-V x_{k}\right\| \\
& =2\left\|V_{k} x_{k}-V x_{k}\right\|+\left\|G z_{k}-z_{k}\right\|,
\end{aligned}
$$


from (31), (33) and (34) we obtain that

$$
\lim _{k \rightarrow \infty}\left\|G V x_{k}-V x_{k}\right\|=0
$$

Also, noting that $\left\|x_{k}-V x_{k}\right\| \leq\left\|x_{k}-V_{k} x_{k}\right\|+\left\|V_{k} x_{k}-V x_{k}\right\|$, from (32) and (33) we get

$$
\lim _{k \rightarrow \infty}\left\|x_{k}-V x_{k}\right\|=0
$$

In addition, observing that

$$
\begin{aligned}
\left\|x_{k}-G x_{k}\right\| & \leq\left\|x_{k}-z_{k}\right\|+\left\|z_{k}-G z_{k}\right\|+\left\|G z_{k}-G x_{k}\right\| \\
& \leq\left\|x_{k}-z_{k}\right\|+\left\|z_{k}-G z_{k}\right\|+\left\|z_{k}-x_{k}\right\| \\
& =2\left\|x_{k}-z_{k}\right\|+\left\|z_{k}-G z_{k}\right\|,
\end{aligned}
$$

from (31) and (32) we get

$$
\lim _{k \rightarrow \infty}\left\|x_{k}-G x_{k}\right\|=0
$$

Since $X$ is reflexive, there exists at least a weak convergence subsequence of $\left\{x_{k}\right\}$, and hence $\omega_{w}\left(x_{k}\right) \neq \emptyset$. Take an arbitrary $p \in \omega_{w}\left(x_{k}\right)$. Then there exists a subsequence $\left\{x_{k_{i}}\right\}$ of $\left\{x_{k}\right\}$ such that $x_{k_{i}} \rightarrow p$. Since $V_{k}$ is nonexpansive for all $k \geq 1, V$ is a nonexpansive selfmapping on $C$. Also, since $X$ is uniformly convex and $V$ and $G$ are two nonexpansive selfmappings on $C$, utilizing Lemma 6 we know from (36) and (37) that $p \in \operatorname{GSVI}(C, A, B)$ and $p \in \operatorname{Fix}(V)=\bigcap_{i=1}^{\infty} \operatorname{Fix}\left(T_{i}\right)$ (due to Lemma 11). Consequently, $p \in \operatorname{Fix}(V)=\bigcap_{i=1}^{\infty} \operatorname{Fix}\left(T_{i}\right) \cap$ $\operatorname{GSVI}(C, A, B)=: \mathcal{F}$. This shows that $\omega_{w}\left(x_{k}\right) \subset \mathcal{F}$.

Step 4. We show that $\omega_{w}\left(x_{k}\right)=\omega_{s}\left(x_{k}\right)$, where

$$
\omega_{s}\left(x_{k}\right)=\left\{x \in C: x_{k_{i}} \rightarrow x \text { for some subsequence }\left\{x_{k_{i}}\right\} \text { of }\left\{x_{k}\right\}\right\} \text {. }
$$

Indeed, by Lemma 9, we have $\left\|G V_{k} x_{k}-z\right\| \leq\left\|x_{k}-z\right\|$ for any fixed $z \in \mathcal{F}$, and hence

$$
\begin{aligned}
\left\|x_{k}-z\right\|^{2}= & \left\|\gamma_{k} \Pi_{C}\left(I-\lambda_{k} F\right) G V_{k} x_{k}+\left(1-\gamma_{k}\right) G V_{k} x_{k}-z\right\|^{2} \\
= & \gamma_{k}\left[\left\langle\Pi_{C}\left(I-\lambda_{k} F\right) G V_{k} x_{k}-\left(I-\lambda_{k} F\right) G V_{k} x_{k}, j\left(x_{k}-z\right)\right\rangle\right. \\
& \left.+\left\langle\lambda_{k}(I-F) G V_{k} x_{k}+\left(1-\lambda_{k}\right) G V_{k} x_{k}-z, j\left(x_{k}-z\right)\right\rangle\right] \\
& +\left(1-\gamma_{k}\right)\left\langle G V_{k} x_{k}-z, j\left(x_{k}-z\right)\right\rangle \\
= & \gamma_{k}\left[\left\langle\Pi_{C}\left(I-\lambda_{k} F\right) G V_{k} x_{k}-\left(I-\lambda_{k} F\right) G V_{k} x_{k}, j\left(\Pi_{C}\left(I-\lambda_{k} F\right) G V_{k} x_{k}-z\right)\right\rangle\right. \\
& +\left\langle\Pi_{C}\left(I-\lambda_{k} F\right) G V_{k} x_{k}-\left(I-\lambda_{k} F\right) G V_{k} x_{k}, j\left(x_{k}-z\right)\right. \\
& \left.-j\left(\Pi_{C}\left(I-\lambda_{k} F\right) G V_{k} x_{k}-z\right)\right\rangle \\
& \left.+\left\langle\lambda_{k}(I-F) G V_{k} x_{k}+\left(1-\lambda_{k}\right) G V_{k} x_{k}-z, j\left(x_{k}-z\right)\right\rangle\right] \\
& +\left(1-\gamma_{k}\right)\left\langle G V_{k} x_{k}-z, j\left(x_{k}-z\right)\right\rangle
\end{aligned}
$$




$$
\begin{aligned}
\leq & \gamma_{k}\left[\left\|\Pi_{C}\left(I-\lambda_{k} F\right) G V_{k} x_{k}-\left(I-\lambda_{k} F\right) G V_{k} x_{k}\right\| \| j\left(x_{k}-z\right)\right. \\
& -j\left(\Pi_{C}\left(I-\lambda_{k} F\right) G V_{k} x_{k}-z\right) \| \\
& \left.+\left\langle\lambda_{k}(I-F) G V_{k} x_{k}+\left(1-\lambda_{k}\right) G V_{k} x_{k}-z, j\left(x_{k}-z\right)\right\rangle\right] \\
& +\left(1-\gamma_{k}\right)\left\langle G V_{k} x_{k}-z, j\left(x_{k}-z\right)\right\rangle \\
\leq & \gamma_{k}\left[\left\|\Pi_{C}\left(I-\lambda_{k} F\right) G V_{k} x_{k}-\left(I-\lambda_{k} F\right) G V_{k} x_{k}\right\| \| j\left(x_{k}-z\right)\right. \\
& -j\left(\Pi_{C}\left(I-\lambda_{k} F\right) G V_{k} x_{k}-z\right) \| \\
& \left.+\lambda_{k}\left\langle(I-F) G V_{k} x_{k}-z, j\left(x_{k}-z\right)\right\rangle+\left(1-\lambda_{k}\right)\left\|x_{k}-z\right\|^{2}\right] \\
& +\left(1-\gamma_{k}\right)\left\|x_{k}-z\right\|^{2} \\
\leq & \gamma_{k}\left(\left\|\Pi_{C}\left(I-\lambda_{k} F\right) G V_{k} x_{k}-G V_{k} x_{k}\right\|\right. \\
& \left.+\lambda_{k}\left\|F\left(G V_{k} x_{k}\right)\right\|\right)\left\|j\left(x_{k}-z\right)-j\left(\Pi_{C}\left(I-\lambda_{k} F\right) G V_{k} x_{k}-z\right)\right\| \\
& +\gamma_{k} \lambda_{k}\left\langle(I-F) G V_{k} x_{k}-z, j\left(x_{k}-z\right)\right\rangle+\left(1-\gamma_{k} \lambda_{k}\right)\left\|x_{k}-z\right\|^{2} \\
\leq & 2 \gamma_{k} \lambda_{k}\left\|F\left(G V_{k} x_{k}\right)\right\|\left\|j\left(x_{k}-z\right)-j\left(\Pi_{C}\left(I-\lambda_{k} F\right) G V_{k} x_{k}-z\right)\right\| \\
& +\gamma_{k} \lambda_{k}\left\langle(I-F) G V_{k} x_{k}-(I-F) z-F(z), j\left(x_{k}-z\right)\right\rangle+\left(1-\gamma_{k} \lambda_{k}\right)\left\|x_{k}-z\right\|^{2} .
\end{aligned}
$$

Therefore, by Lemma 8(b) we get

$$
\begin{aligned}
\left\|x_{k}-z\right\|^{2} \leq & (1-\tau)\left\|x_{k}-z\right\|^{2}-\left\langle F(z), j\left(x_{k}-z\right)\right\rangle \\
& +2\left\|F\left(x_{k}\right)\right\|\left\|j\left(x_{k}-z\right)-j\left(\Pi_{C}\left(I-\lambda_{k} F\right) x_{k}-z\right)\right\|,
\end{aligned}
$$

which immediately leads to

$$
\begin{aligned}
\left\|x_{k}-z\right\|^{2} \leq & \frac{1}{\tau}\left(\left\langle F(z), j\left(z-x_{k}\right)\right\rangle\right. \\
& \left.+2\left\|F\left(G V_{k} x_{k}\right)\right\|\left\|j\left(x_{k}-z\right)-j\left(\Pi_{C}\left(I-\lambda_{k} F\right) G V_{k} x_{k}-z\right)\right\|\right), \quad \forall z \in \mathcal{F},
\end{aligned}
$$

where $\tau=1-\sqrt{\frac{1-\delta}{\zeta}} \in(0,1)$. Note that

$$
\begin{aligned}
\left\|\left(x_{k}-z\right)-\left(\Pi_{C}\left(I-\lambda_{k} F\right) G V_{k} x_{k}-z\right)\right\| & \leq\left\|x_{k}-\left(I-\lambda_{k} F\right) y_{k}\right\| \\
& \leq\left\|x_{k}-y_{k}\right\|+\lambda_{k}\left\|F\left(y_{k}\right)\right\| .
\end{aligned}
$$

Since the uniform smoothness of $X$ guarantees the uniform continuity of $j$ on every nonempty bounded subset of $X$, we deduce from (32), $\lambda_{k} \rightarrow 0$ and the boundedness of $\left\{y_{k}\right\}$ that

$$
\lim _{k \rightarrow \infty}\left\|j\left(x_{k}-z\right)-j\left(\Pi_{C}\left(I-\lambda_{k} F\right) G V_{k} x_{k}-z\right)\right\|=0 .
$$

Now, take an arbitrary $p \in \omega_{w}\left(x_{k}\right)$. Then there exists a subsequence $\left\{x_{k_{i}}\right\}$ of $\left\{x_{k}\right\}$ such that $x_{k_{i}} \rightarrow p$. In terms of Step 3, we know that $p \in \omega_{w}\left(x_{k}\right) \subset \mathcal{F}$. Thus, we can substitute $x_{k_{i}}$ 
for $x_{k}$ and $p$ for $z$ in (38) to get

$$
\begin{aligned}
\left\|x_{k_{i}}-p\right\|^{2} \leq & \frac{1}{\tau}\left(\left\langle F(p), j\left(p-x_{k_{i}}\right)\right\rangle\right. \\
& \left.+2\left\|F\left(y_{k_{i}}\right)\right\|\left\|j\left(x_{k_{i}}-p\right)-j\left(\Pi_{C}\left(I-\lambda_{k_{i}} F\right) y_{k_{i}}-p\right)\right\|\right) .
\end{aligned}
$$

Consequently, the weak convergence of $\left\{x_{k_{i}}\right\}$ to $p$ together with (39) actually implies that $x_{k_{i}} \rightarrow p$ as $i \rightarrow \infty$, and hence $p \in \omega_{s}\left(x_{k}\right)$. This shows that $\omega_{w}\left(x_{k}\right)=\omega_{s}\left(x_{k}\right)$.

Step 5. We show that each $p \in \omega_{s}\left(x_{k}\right)$ solves the variational inequality (19). Indeed, take an arbitrary $p \in \omega_{s}\left(x_{k}\right)$. Then there exists a subsequence $\left\{x_{k_{i}}\right\}$ of $\left\{x_{k}\right\}$ such that $x_{k_{i}} \rightarrow p$ as $i \rightarrow \infty$. According to Steps 3 and 4 , we know that $p \in \omega_{s}\left(x_{k}\right)\left(=\omega_{w}\left(x_{k}\right) \subset \mathcal{F}\right)$. Replacing $x_{k}$ in (39) with $x_{k_{i}}$, and noticing that $x_{k_{i}} \rightarrow p$, we have the Minty type variational inequality

$$
\langle F(z), j(z-p)\rangle \leq 0, \quad \forall z \in \mathcal{F}
$$

which is equivalent to the variational inequality (see Lemma 7)

$$
\langle F(p), j(p-z)| \leq 0, \quad \forall z \in \mathcal{F}
$$

That is, $p \in \mathcal{F}$ is a solution of (19).

Step 6. We show that $\left\{x_{k}\right\}$ converges strongly to a unique solution in $\mathcal{F}$ to VI (19). Indeed, we first claim that the solution set of (19) is a singleton. As a matter of fact, assume that $\bar{p} \in \mathcal{F}$ is also a solution of (19). Then we have

$$
\langle F(\bar{p}), j(\bar{p}-p)\rangle \leq 0
$$

From (40), we have

$$
\langle F(p), j(p-\bar{p})\rangle \leq 0
$$

So, by the $\delta$-strong accretiveness of $F$, we have

$$
\begin{aligned}
& \langle F(\bar{p}), j(\bar{p}-p)\rangle+\langle F(p), j(p-\bar{p})\rangle \leq 0 \\
& \quad \Rightarrow\langle F(\bar{p})-F(p), j(\bar{p}-p)\rangle \leq 0 \\
& \quad \Rightarrow \delta\|\bar{p}-p\|^{2} \leq 0 .
\end{aligned}
$$

Therefore, $\bar{p}=p$. In summary, we have shown that each cluster point of $\left\{x_{k}\right\}$ (as $\left.k \rightarrow \infty\right)$ equals $p$. Consequently, $x_{k} \rightarrow p$ as $k \rightarrow \infty$.

Theorem 6 Let $C, X, \Pi_{C}, A, B, F,\left\{T_{i}\right\}_{i=1}^{\infty}, \mathcal{F}, \delta, \zeta, \lambda$ and $\mu$ be as in Theorem 5 . Let $\left\{V_{k}\right\}_{k=1}^{\infty}$ be defined by (15) and (16). For arbitrarily given $x_{1} \in C$, let $\left\{x_{k}\right\}_{k=1}^{\infty}$ be defined by

$$
\begin{aligned}
x_{k+1}= & \beta_{k} x_{k}+\gamma_{k} \Pi_{C}(I-\lambda A) \Pi_{C}(I-\mu B) V_{k} x_{k} \\
& +\left(1-\beta_{k}-\gamma_{k}\right) \Pi_{C}\left(I-\lambda_{k} F\right) \Pi_{C}(I-\lambda A) \Pi_{C}(I-\mu B) V_{k} x_{k}, \quad \forall k \geq 1,
\end{aligned}
$$

where $\left\{\lambda_{k}\right\},\left\{\beta_{k}\right\}$ and $\left\{\gamma_{k}\right\}$ are three sequences in $[0,1]$ with $\beta_{k}+\gamma_{k} \leq 1, \forall k \geq 1$, and satisfy the following conditions: 
(i) $\lim _{k \rightarrow \infty} \lambda_{k}=0$ and $\sum_{k=1}^{\infty} \lambda_{k}=\infty$;

(ii) $\lim _{k \rightarrow \infty}\left(\frac{\gamma_{k+1}}{1-\beta_{k+1}}-\frac{\gamma_{k}}{1-\beta_{k}}\right)=0$;

(iii) $0<\liminf _{k \rightarrow \infty} \beta_{k} \leq \limsup _{k \rightarrow \infty}\left(\beta_{k}+\gamma_{k}\right)<1$.

Then $\left\{x_{k}\right\}_{k=1}^{\infty}$ converges strongly to a unique solution $x^{*} \in \mathcal{F}$.

Proof Let the mapping $G: C \rightarrow C$ be defined as $G:=\Pi_{C}(I-\lambda A) \Pi_{C}(I-\mu B)$, where $0<\lambda<$ $\frac{\alpha}{\kappa^{2}}$ and $0<\mu<\frac{\beta}{\kappa^{2}}$. In terms of Lemma 4 we know that $G: C \rightarrow C$ is nonexpansive. Then the explicit iterative scheme can be rewritten as

$$
x_{k+1}=\beta_{k} x_{k}+\gamma_{k} G V_{k} x_{k}+\left(1-\beta_{k}-\gamma_{k}\right) \Pi_{C}\left(I-\lambda_{k} F\right) G V_{k} x_{k}, \quad \forall k \geq 1
$$

Next, we divide the rest of the proof into several steps.

Step 1. We show that $\left\{x_{k}\right\}_{k=1}^{\infty}$ is bounded. Indeed, take an arbitrarily given $p \in \mathcal{F}$. Then we have $V_{k} p=p$ and $G p=p$. Hence, by Lemma $8(\mathrm{c})$ we get

$$
\begin{aligned}
\left\|x_{k+1}-p\right\|= & \left\|\beta_{k} x_{k}+\gamma_{k} G V_{k} x_{k}+\left(1-\beta_{k}-\gamma_{k}\right) \Pi_{C}\left(I-\lambda_{k} F\right) G V_{k} x_{k}-p\right\| \\
\leq & \beta_{k}\left\|x_{k}-p\right\|+\gamma_{k}\left\|G V_{k} x_{k}-p\right\|+\left(1-\beta_{k}-\gamma_{k}\right)\left\|\Pi_{C}\left(I-\lambda_{k} F\right) G V_{k} x_{k}-p\right\| \\
\leq & \beta_{k}\left\|x_{k}-p\right\|+\gamma_{k}\left\|x_{k}-p\right\| \\
& +\left(1-\beta_{k}-\gamma_{k}\right)\left\|\left(I-\lambda_{k} F\right) G V_{k} x_{k}-\left(I-\lambda_{k} F\right) p-\lambda_{k} F(p)\right\| \\
\leq & \left(\beta_{k}+\gamma_{k}\right)\left\|x_{k}-p\right\|+\left(1-\beta_{k}-\gamma_{k}\right)\left\|\left(I-\lambda_{k} F\right) G V_{k} x_{k}-\left(I-\lambda_{k} F\right) p\right\| \\
& +\lambda_{k}\left(1-\beta_{k}-\gamma_{k}\right)\|F(p)\| \\
\leq & \left(\beta_{k}+\gamma_{k}\right)\left\|x_{k}-p\right\|+\left(1-\beta_{k}-\gamma_{k}\right)\left(1-\lambda_{k} \tau\right)\left\|G V_{k} x_{k}-p\right\| \\
& +\lambda_{k}\left(1-\beta_{k}-\gamma_{k}\right)\|F(p)\| \\
\leq & {\left[1-\left(1-\beta_{k}-\gamma_{k}\right) \lambda_{k} \tau\right]\left\|x_{k}-p\right\|+\left(1-\beta_{k}-\gamma_{k}\right) \lambda_{k} \tau \frac{\|F(p)\|}{\tau} . }
\end{aligned}
$$

By induction, we conclude that

$$
\left\|x_{k+1}-p\right\| \leq \max \left\{\left\|x_{0}-p\right\|, \frac{\|F(p)\|}{\tau}\right\} .
$$

Therefore, $\left\{x_{k}\right\}_{k=1}^{\infty}$ is bounded. So, the sequences $\left\{z_{k}\right\}_{k=1}^{\infty},\left\{y_{k}\right\}_{k=1}^{\infty}$ and $\left\{F\left(y_{k}\right)\right\}_{k=1}^{\infty}$, where $z_{k}=$ $V_{k} x_{k}$ and $y_{k}=G V_{k} x_{k}$, are also bounded.

Step 2. We show that $\left\|x_{k+1}-x_{k}\right\| \rightarrow 0$ and $\left\|x_{k}-y_{k}\right\| \rightarrow 0$ as $k \rightarrow \infty$. Indeed, observe that

$$
\begin{aligned}
\left\|y_{k+1}-y_{k}\right\| & =\left\|G V_{k+1} x_{k+1}-G V_{k} x_{k}\right\| \\
& \leq\left\|V_{k+1} x_{k+1}-V_{k} x_{k}\right\| \\
& \leq\left\|V_{k+1} x_{k+1}-V_{k+1} x_{k}\right\|+\left\|V_{k+1} x_{k}-V_{k} x_{k}\right\| \\
& \leq\left\|x_{k+1}-x_{k}\right\|+\left\|V_{k} T^{k+1} x_{k}-V_{k} x_{k}\right\| \\
& \leq\left\|x_{k+1}-x_{k}\right\|+\left\|T^{k+1} x_{k}-x_{k}\right\| \\
& =\left\|x_{k+1}-x_{k}\right\|+\alpha_{k+1}\left\|x_{k}-T_{k+1} x_{k}\right\| .
\end{aligned}
$$


Set $x_{k+1}=\beta_{k} x_{k}+\left(1-\beta_{k}\right) w_{k}$ for all $k \geq 1$. Then $w_{k}=\frac{\gamma_{k} y_{k}+\left(1-\beta_{k}-\gamma_{k}\right) \Pi_{C}\left(I-\lambda_{k} F\right) y_{k}}{1-\beta_{k}}$. Note that

$$
\begin{aligned}
& \left\|\Pi_{C}\left(I-\lambda_{k+1} F\right) y_{k+1}-\Pi_{C}\left(I-\lambda_{k} F\right) y_{k}\right\| \\
& \quad \leq\left\|\left(I-\lambda_{k+1} F\right) y_{k+1}-\left(I-\lambda_{k} F\right) y_{k}\right\| \\
& \quad=\left\|y_{k+1}-y_{k}-\lambda_{k+1} F\left(y_{k+1}\right)+\lambda_{k} F\left(y_{k}\right)\right\| \\
& \quad \leq\left\|y_{k+1}-y_{k}\right\|+\lambda_{k+1}\left\|F\left(y_{k+1}\right)\right\|+\lambda_{k}\left\|F\left(y_{k}\right)\right\| \\
& \quad \leq\left\|x_{k+1}-x_{k}\right\|+\lambda_{k+1}\left\|F\left(y_{k+1}\right)\right\|+\lambda_{k}\left\|F\left(y_{k}\right)\right\|+\alpha_{k+1}\left\|x_{k}-T_{k+1} x_{k}\right\| .
\end{aligned}
$$

Hence

$$
\begin{aligned}
& \left\|w_{k+1}-w_{k}\right\| \\
& =\| \frac{\gamma_{k+1} y_{k+1}+\left(1-\beta_{k+1}-\gamma_{k+1}\right) \Pi_{C}\left(I-\lambda_{k+1} F\right) y_{k+1}}{1-\beta_{k+1}} \\
& -\frac{\gamma_{k} y_{k}+\left(1-\beta_{k}-\gamma_{k}\right) \Pi_{C}\left(I-\lambda_{k} F\right) y_{k}}{1-\beta_{k}} \| \\
& \leq\left\|\frac{\gamma_{k+1}}{1-\beta_{k+1}} y_{k+1}-\frac{\gamma_{k}}{1-\beta_{k}} y_{k}\right\| \\
& +\left\|\frac{\left(1-\beta_{k+1}-\gamma_{k+1}\right)}{1-\beta_{k+1}} \Pi_{C}\left(I-\lambda_{k+1} F\right) y_{k+1}-\frac{\left(1-\beta_{k}-\gamma_{k}\right)}{1-\beta_{k}} \Pi_{C}\left(I-\lambda_{k} F\right) y_{k}\right\| \\
& \leq\left|\frac{\gamma_{k+1}}{1-\beta_{k+1}}-\frac{\gamma_{k}}{1-\beta_{k}}\right|\left\|y_{k+1}\right\|+\frac{\gamma_{k}}{1-\beta_{k}} \mid\left\|y_{k+1}-y_{k}\right\| \\
& +\left|\frac{\left(1-\beta_{k+1}-\gamma_{k+1}\right)}{1-\beta_{k+1}}-\frac{\left(1-\beta_{k}-\gamma_{k}\right)}{1-\beta_{k}}\right|\left\|\Pi_{C}\left(I-\lambda_{k+1} F\right) y_{k+1}\right\| \\
& +\frac{\left(1-\beta_{k}-\gamma_{k}\right)}{1-\beta_{k}}\left\|\Pi_{C}\left(I-\lambda_{k+1} F\right) y_{k+1}-\Pi_{C}\left(I-\lambda_{k} F\right) y_{k}\right\| \\
& \leq\left|\frac{\gamma_{k+1}}{1-\beta_{k+1}}-\frac{\gamma_{k}}{1-\beta_{k}}\right|\left(\left\|y_{k+1}\right\|+\left\|\Pi_{C}\left(I-\lambda_{k+1} F\right) y_{k+1}\right\|\right) \\
& +\frac{\gamma_{k}}{1-\beta_{k}} \mid\left(\left\|x_{k+1}-x_{k}\right\|+\alpha_{k+1}\left\|x_{k}-T_{k+1} x_{k}\right\|\right) \\
& +\frac{\left(1-\beta_{k}-\gamma_{k}\right)}{1-\beta_{k}}\left(\left\|x_{k+1}-x_{k}\right\|+\lambda_{k+1}\left\|F\left(y_{k+1}\right)\right\|+\lambda_{k}\left\|F\left(y_{k}\right)\right\|+\alpha_{k+1}\left\|x_{k}-T_{k+1} x_{k}\right\|\right) \\
& \leq\left|\frac{\gamma_{k+1}}{1-\beta_{k+1}}-\frac{\gamma_{k}}{1-\beta_{k}}\right|\left(\left\|y_{k+1}\right\|+\left\|\Pi_{C}\left(I-\lambda_{k+1} F\right) y_{k+1}\right\|\right) \\
& +\left\|x_{k+1}-x_{k}\right\|+\lambda_{k+1}\left\|F\left(y_{k+1}\right)\right\|+\lambda_{k}\left\|F\left(y_{k}\right)\right\|+\alpha_{k+1}\left(\left\|x_{k}\right\|+\left\|T_{k+1} x_{k}\right\|\right) \text {. }
\end{aligned}
$$

Since $\left\{x_{k}\right\},\left\{y_{k}\right\}$ and $\left\{F\left(y_{k}\right)\right\}$ are bounded, we have that $\left\{\left\|y_{k+1}\right\|+\left\|\Pi_{C}\left(I-\lambda_{k+1} F\right) y_{k+1}\right\|\right\}$ and $\left\{\left\|x_{k}\right\|+\left\|T_{k+1} x_{k}\right\|\right\}$ are bounded. So it follows from $\alpha_{k} \rightarrow 0$ and conditions (i) and (ii) that

$$
\limsup _{k \rightarrow \infty}\left(\left\|w_{k+1}-w_{k}\right\|-\left\|x_{k+1}-x_{k}\right\|\right) \leq 0
$$

Hence, by Lemma 12 , we get $\left\|w_{k}-x_{k}\right\| \rightarrow 0$ as $k \rightarrow \infty$. Consequently,

$$
\lim _{k \rightarrow \infty}\left\|x_{k+1}-x_{k}\right\|=\lim _{k \rightarrow \infty}\left(1-\beta_{k}\right)\left\|w_{k}-x_{k}\right\|=0
$$


We also note that

$$
\begin{aligned}
\left\|w_{k}-y_{k}\right\| & =\left\|\frac{\gamma_{k} y_{k}+\left(1-\beta_{k}-\gamma_{k}\right) \Pi_{C}\left(I-\lambda_{k} F\right) y_{k}}{1-\beta_{k}}-y_{k}\right\| \\
& =\frac{1-\beta_{k}-\gamma_{k}}{1-\beta_{k}}\left\|\Pi_{C}\left(I-\lambda_{k} F\right) y_{k}-y_{k}\right\| \\
& \leq\left\|\Pi_{C}\left(I-\lambda_{k} F\right) y_{k}-\Pi_{C} y_{k}\right\| \\
& \leq \lambda_{k}\left\|F\left(y_{k}\right)\right\| \rightarrow 0 \quad \text { as } k \rightarrow \infty .
\end{aligned}
$$

It follows that

$$
\lim _{k \rightarrow \infty}\left\|x_{k}-y_{k}\right\|=0
$$

Step 3. We show that $\left\|z_{k}-G z_{k}\right\| \rightarrow 0$ and $\left\|x_{k}-V_{k} x_{k}\right\| \rightarrow 0$ as $k \rightarrow \infty$. Indeed, for simplicity, put $q=\Pi_{C}(p-\mu B p)$ and $u_{k}=\Pi_{C}\left(z_{k}-\mu B z_{k}\right)$. Then $y_{k}=G z_{k}=\Pi_{C}\left(u_{k}-\lambda A u_{k}\right)$ for all $k \geq 1$. Repeating the same arguments as those of (24), we obtain

$$
\left\|y_{k}-p\right\|^{2} \leq\left\|x_{k}-p\right\|^{2}-2 \mu\left(\beta-\kappa^{2} \mu\right)\left\|B z_{k}-B p\right\|^{2}-2 \lambda\left(\alpha-\kappa^{2} \lambda\right)\left\|A u_{k}-A q\right\|^{2} .
$$

Observe that

$$
\begin{aligned}
\left\|x_{k+1}-p\right\|^{2} \leq & \beta_{k}\left\|x_{k}-p\right\|^{2}+\gamma_{k}\left\|G V_{k} x_{k}-p\right\|^{2}+\left(1-\beta_{k}-\gamma_{k}\right)\left\|\Pi_{C}\left(I-\lambda_{k} F\right) G V_{k} x_{k}-p\right\|^{2} \\
\leq & \beta_{k}\left\|x_{k}-p\right\|^{2}+\gamma_{k}\left\|G V_{k} x_{k}-p\right\|^{2} \\
& +\left(1-\beta_{k}-\gamma_{k}\right)\left\|\left(I-\lambda_{k} F\right) G V_{k} x_{k}-\left(I-\lambda_{k} F\right) p-\lambda_{k} F(p)\right\|^{2} \\
\leq & \beta_{k}\left\|x_{k}-p\right\|^{2}+\gamma_{k}\left\|G V_{k} x_{k}-p\right\|^{2} \\
& +\left(1-\beta_{k}-\gamma_{k}\right)\left[\left(1-\lambda_{k} \tau\right)\left\|G V_{k} x_{k}-p\right\|+\lambda_{k} F(p) \|\right]^{2} \\
\leq & \beta_{k}\left\|x_{k}-p\right\|^{2}+\gamma_{k}\left\|G V_{k} x_{k}-p\right\|^{2} \\
& +\left(1-\beta_{k}-\gamma_{k}\right)\left[\left(1-\lambda_{k} \tau\right)\left\|G V_{k} x_{k}-p\right\|^{2}+\lambda_{k} \tau^{-1}\|F(p)\|^{2}\right] \\
\leq & \beta_{k}\left\|x_{k}-p\right\|^{2}+\gamma_{k}\left\|G V_{k} x_{k}-p\right\|^{2} \\
& +\left(1-\beta_{k}-\gamma_{k}\right)\left\|G V_{k} x_{k}-p\right\|^{2}+\lambda_{k} \tau^{-1}\|F(p)\|^{2} \\
= & \beta_{k}\left\|x_{k}-p\right\|^{2}+\left(1-\beta_{k}\right)\left\|G V_{k} x_{k}-p\right\|^{2}+\lambda_{k} \tau^{-1}\|F(p)\|^{2},
\end{aligned}
$$

which together with (44) implies that

$$
\begin{aligned}
\left\|x_{k+1}-p\right\|^{2} \leq & \beta_{k}\left\|x_{k}-p\right\|^{2}+\left(1-\beta_{k}\right)\left[\left\|x_{k}-p\right\|^{2}-2 \mu\left(\beta-\kappa^{2} \mu\right)\left\|B z_{k}-B p\right\|^{2}\right. \\
& \left.-2 \lambda\left(\alpha-\kappa^{2} \lambda\right)\left\|A u_{k}-A q\right\|^{2}\right]+\lambda_{k} \tau^{-1}\|F(p)\|^{2} \\
= & \left\|x_{k}-p\right\|^{2}-2\left(1-\beta_{k}\right)\left[\mu\left(\beta-\kappa^{2} \mu\right)\left\|B z_{k}-B p\right\|^{2}\right. \\
& \left.+\lambda\left(\alpha-\kappa^{2} \lambda\right)\left\|A u_{k}-A q\right\|^{2}\right]+\lambda_{k} \tau^{-1}\|F(p)\|^{2} .
\end{aligned}
$$


So, it follows that

$$
\begin{aligned}
2(1 & \left.-\beta_{k}\right)\left[\mu\left(\beta-\kappa^{2} \mu\right)\left\|B z_{k}-B p\right\|^{2}+\lambda\left(\alpha-\kappa^{2} \lambda\right)\left\|A u_{k}-A q\right\|^{2}\right] \\
& \leq\left\|x_{k}-p\right\|^{2}-\left\|x_{k+1}-p\right\|^{2}+\lambda_{k} \tau^{-1}\|F(p)\|^{2} \\
& \leq\left\|x_{k}-x_{k+1}\right\|\left(\left\|x_{k}-p\right\|+\left\|x_{k+1}-p\right\|\right)+\lambda_{k} \tau^{-1}\|F(p)\|^{2} .
\end{aligned}
$$

Since $\lambda \in\left(0, \frac{\alpha}{\kappa^{2}}\right), \mu \in\left(0, \frac{\beta}{\kappa^{2}}\right)$ and $\lambda_{k} \rightarrow 0$ as $k \rightarrow \infty$, we deduce from (42) and condition (iii) that

$$
\lim _{k \rightarrow \infty}\left\|B z_{k}-B p\right\|=0 \quad \text { and } \quad \lim _{k \rightarrow \infty}\left\|A u_{k}-A q\right\|=0
$$

Repeating the same arguments as those of (28), we get

$$
\begin{gathered}
\left\|y_{k}-p\right\|^{2} \leq\left\|x_{k}-p\right\|^{2}-g_{1}\left(\left\|z_{k}-u_{k}-(p-q)\right\|\right)-g_{2}\left(\left\|u_{k}-y_{k}+(p-q)\right\|\right) \\
+2 \mu\left\|B p-B z_{k}\right\|\left\|u_{k}-q\right\|+2 \lambda\left\|A q-A u_{k}\right\|\left\|y_{k}-p\right\| .
\end{gathered}
$$

Combining (45) and (48), we have

$$
\begin{aligned}
\left\|x_{k+1}-p\right\|^{2} \leq & \beta_{k}\left\|x_{k}-p\right\|^{2}+\left(1-\beta_{k}\right)\left[\left\|x_{k}-p\right\|^{2}-g_{1}\left(\left\|z_{k}-u_{k}-(p-q)\right\|\right)\right. \\
& -g_{2}\left(\left\|u_{k}-y_{k}+(p-q)\right\|\right)+2 \mu\left\|B p-B z_{k}\right\|\left\|u_{k}-q\right\| \\
& \left.+2 \lambda\left\|A q-A u_{k}\right\|\left\|y_{k}-p\right\|\right]+\lambda_{k} \tau^{-1}\|F(p)\|^{2} \\
\leq & \left\|x_{k}-p\right\|^{2}-\left(1-\beta_{k}\right)\left[g_{1}\left(\left\|z_{k}-u_{k}-(p-q)\right\|\right)+g_{2}\left(\left\|u_{k}-y_{k}+(p-q)\right\|\right)\right] \\
& +2 \mu\left\|B p-B z_{k}\right\|\left\|u_{k}-q\right\|+2 \lambda\left\|A q-A u_{k}\right\|\left\|y_{k}-p\right\|+\lambda_{k} \tau^{-1}\|F(p)\|^{2},
\end{aligned}
$$

which immediately leads to

$$
\begin{aligned}
(1- & \left.\beta_{k}\right)\left[g_{1}\left(\left\|z_{k}-u_{k}-(p-q)\right\|\right)+g_{2}\left(\left\|u_{k}-y_{k}+(p-q)\right\|\right)\right] \\
\leq & \left\|x_{k}-p\right\|^{2}-\left\|x_{k+1}-p\right\|^{2} \\
& +2 \mu\left\|B p-B z_{k}\right\|\left\|u_{k}-q\right\|+2 \lambda\left\|A q-A u_{k}\right\|\left\|y_{k}-p\right\|+\lambda_{k} \tau^{-1}\|F(p)\|^{2} \\
\leq & \left\|x_{k}-x_{k+1}\right\|\left(\left\|x_{k}-p\right\|+\left\|x_{k+1}-p\right\|\right) \\
& +2 \mu\left\|B p-B z_{k}\right\|\left\|u_{k}-q\right\|+2 \lambda\left\|A q-A u_{k}\right\|\left\|y_{k}-p\right\|+\lambda_{k} \tau^{-1}\|F(p)\|^{2} .
\end{aligned}
$$

Since $\lambda_{k} \rightarrow 0$ as $k \rightarrow \infty$, and $\left\{u_{k}\right\}$ and $\left\{y_{k}\right\}$ are bounded, we deduce from (42), (47) and condition (iii) that

$$
\lim _{k \rightarrow \infty} g_{1}\left(\left\|z_{k}-u_{k}-(p-q)\right\|\right)=0 \quad \text { and } \quad \lim _{k \rightarrow \infty} g_{2}\left(\left\|u_{k}-y_{k}+(p-q)\right\|\right)=0 .
$$

Utilizing the properties of $g_{1}$ and $g_{2}$, we conclude that

$$
\lim _{k \rightarrow \infty}\left\|z_{k}-u_{k}-(p-q)\right\|=0 \quad \text { and } \quad \lim _{k \rightarrow \infty}\left\|u_{k}-y_{k}+(p-q)\right\|=0
$$


From (49), we get

$$
\left\|z_{k}-y_{k}\right\| \leq\left\|z_{k}-u_{k}-(p-q)\right\|+\left\|u_{k}-y_{k}+(p-q)\right\| \rightarrow 0 \quad \text { as } k \rightarrow \infty
$$

That is,

$$
\lim _{k \rightarrow \infty}\left\|z_{k}-G z_{k}\right\|=\lim _{k \rightarrow \infty}\left\|z_{k}-y_{k}\right\|=0
$$

This together with (43) implies that

$$
\lim _{k \rightarrow \infty}\left\|x_{k}-V_{k} x_{k}\right\|=\lim _{k \rightarrow \infty}\left\|x_{k}-z_{k}\right\|=0
$$

Step 4. We show that $\omega_{w}\left(x_{k}\right) \subset \mathcal{F}$, where

$$
\omega_{w}\left(x_{k}\right)=\left\{x \in C: x_{k_{i}} \rightarrow x \text { for some subsequence }\left\{x_{k_{i}}\right\} \text { of }\left\{x_{k}\right\}\right\} .
$$

Indeed, repeating the same arguments as those of (36) and (37) in the proof of Theorem 5, we obtain that

$$
\lim _{k \rightarrow \infty}\left\|x_{k}-V x_{k}\right\|=0 \quad \text { and } \quad \lim _{k \rightarrow \infty}\left\|x_{k}-G x_{k}\right\|=0
$$

Utilizing Lemma 6 and Lemma 11 and the nonexpansivity of $V$ and $G$, we conclude that $\omega_{w}\left(x_{k}\right) \subset \mathcal{F}$.

Step 5. We show that $\lim \sup _{k \rightarrow \infty}\left\langle F\left(x^{*}\right), j\left(x^{*}-v_{k}\right)\right\rangle \leq 0$, where $v_{k}=\Pi_{C}\left(I-\lambda_{k} F\right) y_{k}$ for all $k \geq 1$ and $x^{*} \in \mathcal{F}$ is the unique solution of VI (19). Indeed, we first take a subsequence $\left\{v_{k_{i}}\right\}$ of $\left\{v_{k}\right\}$ such that

$$
\limsup _{k \rightarrow \infty}\left\langle F\left(x^{*}\right), j\left(x^{*}-v_{k}\right)\right\rangle=\lim _{i \rightarrow \infty}\left\langle F\left(x^{*}\right), j\left(x^{*}-v_{k_{i}}\right)\right\rangle .
$$

We may also assume that $v_{k_{i}} \rightarrow z$. Note that

$$
\begin{aligned}
\left\|v_{k}-x_{k}\right\| & =\left\|\Pi_{C}\left(I-\lambda_{k} F\right) y_{k}-x_{k}\right\| \\
& \leq\left\|\left(I-\lambda_{k} F\right) y_{k}-x_{k}\right\| \leq\left\|y_{k}-x_{k}\right\|+\lambda_{k}\left\|F\left(y_{k}\right)\right\| \rightarrow 0 \quad \text { as } k \rightarrow \infty .
\end{aligned}
$$

Combining (53) with $\omega_{w}\left(x_{k}\right) \subset \mathcal{F}$ (due to Step 4), we get $z \in \mathcal{F}$. So, it follows from VI (19) that

$$
\begin{aligned}
\limsup _{k \rightarrow \infty}\left\langle F\left(x^{*}\right), j\left(x^{*}-v_{k}\right)\right\rangle & =\lim _{i \rightarrow \infty}\left\langle F\left(x^{*}\right), j\left(x^{*}-v_{k_{i}}\right)\right\rangle \\
& =\left\langle F\left(x^{*}\right), j\left(x^{*}-z\right)\right\rangle \leq 0 .
\end{aligned}
$$

Since $v_{k}=\Pi_{C}\left(I-\lambda_{k} F\right) y_{k}$ for all $k \geq 1$, according to Lemma 2(iii), we have

$$
\left\langle\left(I-\lambda_{k} F\right) y_{k}-\Pi_{C}\left(I-\lambda_{k} F\right) y_{k}, j\left(x^{*}-v_{k}\right)\right\rangle \leq 0
$$


From (54), we have

$$
\begin{aligned}
\left\|v_{k}-x^{*}\right\|^{2}= & \left\langle\Pi_{C}\left(I-\lambda_{k} F\right) y_{k}-x^{*}, j\left(v_{k}-x^{*}\right)\right\rangle \\
= & \left\langle\Pi_{C}\left(I-\lambda_{k} F\right) y_{k}-\left(I-\lambda_{k} F\right) y_{k}, j\left(v_{k}-x^{*}\right)\right\rangle \\
& +\left\langle\left(I-\lambda_{k} F\right) y_{k}-x^{*}, j\left(v_{k}-x^{*}\right)\right\rangle \\
\leq & \left\langle\left(I-\lambda_{k} F\right) y_{k}-x^{*}, j\left(v_{k}-x^{*}\right)\right\rangle \\
= & \left\langle\left(I-\lambda_{k} F\right) y_{k}-\left(I-\lambda_{k} F\right) x^{*}, j\left(v_{k}-x^{*}\right)\right\rangle+\lambda_{k}\left\langle F\left(x^{*}\right), j\left(x^{*}-v_{k}\right)\right\rangle \\
\leq & \left(1-\lambda_{k} \tau\right)\left\|y_{k}-x^{*}\right\|\left\|v_{k}-x^{*}\right\|+\lambda_{k}\left\langle F\left(x^{*}\right), j\left(x^{*}-v_{k}\right)\right\rangle \\
\leq & \frac{1}{2}\left(1-\lambda_{k} \tau\right)^{2}\left\|y_{k}-x^{*}\right\|^{2}+\frac{1}{2}\left\|v_{k}-x^{*}\right\|^{2}+\lambda_{k}\left\langle F\left(x^{*}\right), j\left(x^{*}-v_{k}\right)\right\rangle,
\end{aligned}
$$

which immediately yields

$$
\begin{aligned}
\left\|v_{k}-x^{*}\right\|^{2} & \leq\left(1-\lambda_{k} \tau\right)\left\|y_{k}-x^{*}\right\|^{2}+2 \lambda_{k}\left\langle F\left(x^{*}\right), j\left(x^{*}-v_{k}\right)\right\rangle \\
& \leq\left(1-\lambda_{k} \tau\right)\left\|x_{k}-x^{*}\right\|^{2}+2 \lambda_{k}\left\langle F\left(x^{*}\right), j\left(x^{*}-v_{k}\right)\right\rangle .
\end{aligned}
$$

Step 6. We show that $x_{k} \rightarrow x^{*}$ as $k \rightarrow \infty$. Indeed, from (45) and (55), we have

$$
\begin{aligned}
\left\|x_{k+1}-x^{*}\right\|^{2} \leq & \beta_{k}\left\|x_{k}-x^{*}\right\|^{2}+\gamma_{k}\left\|y_{k}-x^{*}\right\|^{2}+\left(1-\beta_{k}-\gamma_{k}\right)\left\|v_{k}-x^{*}\right\|^{2} \\
\leq & \beta_{k}\left\|x_{k}-x^{*}\right\|^{2}+\gamma_{k}\left\|x_{k}-x^{*}\right\|^{2} \\
& +\left(1-\beta_{k}-\gamma_{k}\right)\left[\left(1-\lambda_{k} \tau\right)\left\|x_{k}-x^{*}\right\|^{2}+2 \lambda_{k}\left\langle F\left(x^{*}\right), j\left(x^{*}-v_{k}\right)\right\rangle\right] \\
= & {\left[1-\lambda_{k}\left(1-\beta_{k}-\gamma_{k}\right) \tau\right]\left\|x_{k}-x^{*}\right\|^{2} } \\
& +\lambda_{k}\left(1-\beta_{k}-\gamma_{k}\right) \tau \cdot \frac{2}{\tau}\left\langle F\left(x^{*}\right), j\left(x^{*}-v_{k}\right)\right\rangle .
\end{aligned}
$$

Since $\sum_{k=1}^{\infty} \lambda_{k}=\infty, \lim \sup _{k \rightarrow \infty}\left(\beta_{k}+\gamma_{k}\right)<1$ and $\tau=1-\sqrt{\frac{1-\delta}{\zeta}} \in(0,1)$, we get

$$
\sum_{k=1}^{\infty} \lambda_{k}\left(1-\beta_{k}-\gamma_{k}\right) \tau=\infty
$$

Taking into account $\lim \sup _{k \rightarrow \infty}\left\langle F\left(x^{*}\right), j\left(x^{*}-v_{k}\right)\right\rangle \leq 0$, we can apply Lemma 13 to relation (56) and conclude that $x_{k} \rightarrow x^{*}$ as $k \rightarrow \infty$.

\section{Acknowledgements}

This research was partially supported by the Innovation Program of Shanghai Municipal Education Commission (15ZZ068), Ph.D. Program Foundation of Ministry of Education of China (20123127110002) and Program for Outstanding Academic Leaders in Shanghai City (15XD1503100). This research was partially supported by the grant MOST 106-2115-M-037-001, and the grant from Research Center for Nonlinear Analysis and Optimization, Kaohsiung Medical University, Taiwan.

\section{Competing interests}

The authors declare that they have no competing interests.

\section{Authors' contributions}

All authors contributed equally to the writing of this paper. All authors read and approved the final manuscript. 


\section{Author details}

'Department of Mathematics, Shanghai Normal University, Shanghai, 200234, China. ${ }^{2}$ Department of Industrial Management, Vanung University, Taoyuan, Taiwan. ${ }^{3}$ Center for Fundamental Science; and Research Center for Nonlinear Analysis and Optimization, Kaohsiung Medical University, Kaohsiung, 80702, Taiwan. ${ }^{4}$ Department of Medical Research, Kaohsiung Medical University Hospital, Kaohsiung, 80702, Taiwan.

\section{Publisher's Note}

Springer Nature remains neutral with regard to jurisdictional claims in published maps and institutional affiliations.

Received: 2 April 2017 Accepted: 18 September 2017 Published online: 04 October 2017

\section{References}

1. Cioranescu, I: Geometry of Banach Spaces, Duality Mappings and Nonlinear Problems. Kluwer, Dordrecht (1990)

2. Yao, Y, Liou, YC, Kang, SM, Yu, Y: Algorithms with strong convergence for a system of nonlinear variational inequalities in Banach spaces. Nonlinear Anal. 74(17), 6024-6034 (2011)

3. Ceng, LC, Gupta, H, Ansari, QH: Implicit and explicit algorithms for a system of nonlinear variational inequalities in Banach spaces. J. Nonlinear Convex Anal. 16(5), 1-20 (2015)

4. Ceng, LC, Wang, CY, Yao, JC: Strong convergence theorems by a related extragradient method for a general system of variational inequalities. Math. Methods Oper. Res. 67, 375-390 (2008)

5. Verma, RU: On a new system of nonlinear variational inequalities and associated iterative algorithms. Math. Sci. Res. Hot-Line 3, 65-68 (1999)

6. Verma, RU: Projection methods, algorithms and a new system of nonlinear variational inequalities. Comput. Math. Appl. 41, 1025-1031 (2001)

7. Facchinei, F, Pang, JS: Finite-Dimensional Variational Inequalities and Complementarity Problems I. Springer, New York (2003)

8. Glowinski, R, Lions, JL, Tremolieres, R: Numerical Analysis and Variational Inequalities. North-Holland, Amsterdam (1981)

9. Yao, YH, Chen, R, Xu, HK: Schemes for finding minimum-norm solutions of variational inequalities. Nonlinear Anal. 72 , 3447-3456 (2010)

10. Yao, YH, Liou, YC, Kang, SM: Approach to common elements of variational inequality problems and fixed point problems via a relaxed extragradient method. Comput. Math. Appl. 59, 3472-3480 (2010)

11. Yao, YH, Noor, MA, Liou, YC, Kang, SM: Iterative algorithms for general multivalued variational inequalities. Abstr. Appl. Anal. 2012, Article ID 768272 (2012)

12. Zegeye, H, Shahzad, N, Yao, YH: Minimum-norm solution of variational inequality and fixed point problem in Banach spaces. Optimization 64, 453-471 (2015)

13. Korpelevich, GM: An extragradient method for finding saddle points and for other problems. Èkon. Mat. Metody 12 747-756 (1976)

14. Yao, YH, Noor, MA, Liou, YC: Strong convergence of a modified extragradient method to the minimum-norm solution of variational inequalities. Abstr. Appl. Anal. 2012, Article ID 817436 (2012)

15. Yao, YH, Postolache, M, Liou, YC, Yao, Z: Construction algorithms for a class of monotone variational inequalities. Optim. Lett. 10, 1519-1528 (2016)

16. Aoyama, K, liduka, H, Takahashi, W: Weak convergence of an iterative sequence for accretive operators in Banach spaces. Fixed Point Theory Appl. 2006, 35390 (2006)

17. Yamada, I: The hybrid steepest-descent method for the variational inequality problems over the intersection of the fixed-point sets of nonexpansive mappings. In: Batnariu, D, Censor, Y, Reich, S (eds.) Inherently Parallel Algorithms in Feasibility and Optimization and Their Applications, pp. 473-504. North-Holland, Amsterdam (2001)

18. Buong, N, Phuong, NTH: Strong convergence to solutions for a class of variational inequalities in Banach spaces by implicit iteration methods. J. Optim. Theory Appl. 159, 399-411 (2013)

19. Zeng, LC, Yao, JC: Implicit iteration scheme with perturbed mapping for common fixed points of a finite family of nonexpansive mappings. Nonlinear Anal. 64, 2507-2515 (2006)

20. Ceng, LC, Petrusel, A, Yao, JC: Implicit iteration scheme with perturbed mapping for common fixed points of a finite family of Lipschitz pseudocontractive mappings. J. Math. Inequal. 1, 243-258 (2007)

21. Buong, N, Anh, NTQ: An implicit iteration method for variational inequalities over the set of common fixed points of a finite family of nonexpansive mappings in Hilbert spaces. Fixed Point Theory Appl. 2011, 276859 (2011)

22. Kamimura, S, Takahashi, W: Strong convergence of a proximal-type algorithm in a Banach space. SIAM J. Optim. 13, 938-945 (2002)

23. Goebel, K, Reich, S: Uniform Convexity, Hyperbolic Geometry, and Nonexpansive Mappings. Dekker, New York (1984)

24. Takahashi, Y, Hashimoto, K, Kato, M: On sharp uniform convexity, smoothness, and strong type, cotype inequalities. J. Nonlinear Convex Anal. 3, 267-281 (2002)

25. Xu, HK: Inequalities in Banach spaces with applications. Nonlinear Anal. 16, 1127-1138 (1991)

26. Reich, S: Weak convergence theorems for nonexpansive mappings in Banach spaces. J. Math. Anal. Appl. 67, 274-276 (1979)

27. Yao, YH, Liou, YC, Kang, SM: Two-step projection methods for a system of variational inequality problems in Banach spaces. J. Glob. Optim. 55, 801-811 (2013)

28. Zeidler, E: Nonlinear Functional Analysis and Its Applications III: Variational Methods and Applications. Springer, New York (1985)

29. Ceng, LC, Ansari, QH, Yao, JC: Mann-type steepest-descent and modified steepest-descent methods for variational inequalities in Banach spaces. Numer. Funct. Anal. Optim. 29(9-10), 987-1033 (2008)

30. Takahashi, W: Weak and strong convergence theorems for families of nonexpansive mappings and their applications. Ann. Univ. Mariae Curie-Skłodowska, Sect. A 51, 277-292 (1997) 
31. Kikkawa, M, Takahashi, W: Strong convergence theorems by the viscosity approximation methods for a countable family of nonexpansive mappings. Taiwan. J. Math. 12(3), 583-598 (2008)

32. Browder, FE: Nonexpansive nonlinear operators in a Banach space. Proc. Natl. Acad. Sci. USA 54, 1041-1044 (1965)

33. Suzuki, T: Strong convergence of Krasnoselskii and Mann's type sequences for one-parameter nonexpansive semigroups without Bochner integrals. J. Math. Anal. Appl. 305, 227-239 (2005)

34. Xu, HK: Iterative algorithms for nonlinear operators. J. Lond. Math. Soc. 66, 240-256 (2002)

Submit your manuscript to a SpringerOpen ${ }^{\circ}$ journal and benefit from:

- Convenient online submission

$\checkmark$ Rigorous peer review

- Open access: articles freely available online

- High visibility within the field

Retaining the copyright to your article

Submit your next manuscript at $\gg$ springeropen.com 